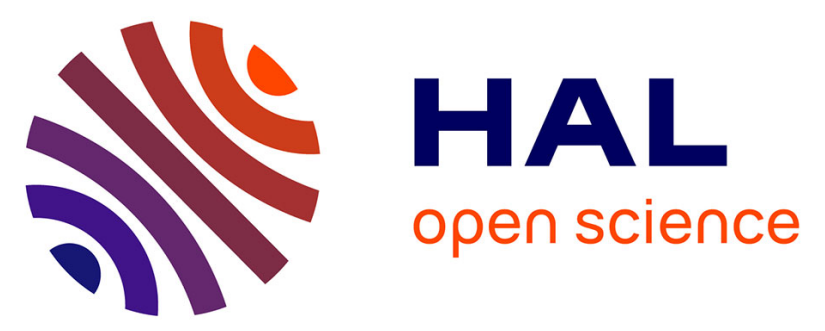

\title{
OS vs. NS intramolecular nonbonded interactions in neutral and radical cation salts of TTF-oxazoline derivatives: synthesis, theoretical investigations, crystalline structures, and physical properties
}

Céline Réthoré, Augustin Madalan, Marc Fourmigué, Enric Canadell, Elsa B. Lopes, Manuel Almeida, Rodolphe Clérac, Narcis Avarvari

\section{To cite this version:}

Céline Réthoré, Augustin Madalan, Marc Fourmigué, Enric Canadell, Elsa B. Lopes, et al.. OS vs. NS intramolecular nonbonded interactions in neutral and radical cation salts of TTF-oxazoline derivatives: synthesis, theoretical investigations, crystalline structures, and physical properties. New Journal of Chemistry, 2007, 31, pp.1468-1483. 10.1039/B701617D . hal-00189195

\section{HAL Id: hal-00189195 https://hal.science/hal-00189195}

Submitted on 23 Aug 2013

HAL is a multi-disciplinary open access archive for the deposit and dissemination of scientific research documents, whether they are published or not. The documents may come from teaching and research institutions in France or abroad, or from public or private research centers.
L'archive ouverte pluridisciplinaire HAL, est destinée au dépôt et à la diffusion de documents scientifiques de niveau recherche, publiés ou non, émanant des établissements d'enseignement et de recherche français ou étrangers, des laboratoires publics ou privés. 


\title{
O...S vs. $\mathrm{N}$...S intramolecular nonbonded interactions in neutral and radical cation salts of TTF-oxazoline derivatives: synthesis, theoretical investigations, crystalline structures, and physical properties $\dagger$
}

\author{
Céline Réthoré, ${ }^{a}$ Augustin Madalan, ${ }^{a}$ Marc Fourmigué, ${ }^{* a}$ Enric Canadell, ${ }^{b}$ \\ Elsa B. Lopes, ${ }^{c}$ Manuel Almeida, ${ }^{c}$ Rodolphe Clérac ${ }^{d}$ and Narcis Avarvari ${ }^{a} a$
}

Received (in Montpellier, France) 2nd February 2007, Accepted 5th April 2007

First published as an Advance Article on the web 8th May 2007

DOI: $10.1039 / b 701617 d$

Racemic and enantiopure ethylenedithio-tetrathiafulvalene-thiomethyl-oxazoline (EDT-TTF(SMe)-OX) derivatives have been synthesized. Single-crystal X-ray diffraction analyses reveal the establishment of $\mathrm{O} \cdots \mathrm{S}$ nonbonded interactions, unprecedented in the TTF series, characterized by short S...O distances and linear O ‥SMe motifs. Theoretical calculations at the DFT/B3LYP level on a model molecule demonstrate that both possible planar $s$-trans $(\mathrm{O} \cdots \mathrm{S}$ interaction) and $s$-cis (N...S interaction) conformations are energy minima, separated by an extremely weak energy gap. The energy barrier corresponding to the equilibrium between the two forms has been also estimated from DFT calculations, as well as their relative stability in the radical cation state of the TTF. According to the latter, there is a slight tendency towards the enhancement of the $\mathrm{N}$...S interactions. Following the predictions of the theoretical calculations, the coexistence of both $\mathrm{O} \cdots \mathrm{S}$ and $\mathrm{N} \cdots \mathrm{S}$ nonbonded interactions is observed in two mixed valence radical cation salts of the racemic TTF with the dianionic cluster $\mathrm{Mo}_{6} \mathrm{Cl}_{14}$, prepared upon electrocrystallization. Interestingly, the ratio TTF : dianion is finely tuned by the choice of the electrocrystallization solvent. Physical measurements such as electrical conductivity and thermoelectric power on single crystals combined with magnetic susceptibility data in one case and extended Hückel tight-binding calculations demonstrate and rationalize the semiconducting behavior of both mixed valence salts. This study demonstrates that intramolecular $\mathrm{N} \cdots \mathrm{S}$ and $\mathrm{O} \cdots \mathrm{S}$ interactions can efficiently modulate and direct in the TTF series the occurrence of original solid-state structures provided with physical properties.

\section{Introduction}

Intra- and intermolecular nonbonded interactions (or secondary-bonding interactions) between heavier chalcogens $(\mathrm{E}=\mathrm{S}, \mathrm{Se})$ and oxygen or nitrogen atoms have been shown to be responsible for controlling the conformation of a large number of molecules. ${ }^{1}$ As a general feature, the nonbonded E...O or E $\cdots \mathrm{N}$ distances are significantly shorter than the sum of the corresponding van der Waals radii in the crystalline structures or optimized geometries of the investigated compounds. $^{2}$ These interactions may play important roles in the structure and biological activity of certain organic sulfur

${ }^{a}$ Laboratoire Chimie, Ingénierie Moléculaire et Matériaux

(CIMMA), UMR 6200 CNRS-Université d'Angers, UFR Sciences,

Bât. K, 2 Bd. Lavoisier, 49045 Angers, France. E-mail:

marc.fourmigue@univ-rennes1.fr; narcis.avarvari@univ-angers.fr, Fax: (+33)0241735405

${ }^{b}$ Institut de Ciència de Materials de Barcelona (CSIC), Campus de la UAB, E-08193 Bellaterra, Spain

${ }^{c}$ Dept. Química, ITN, P-2686-953 Sacavém, Portugal

${ }^{d}$ Centre de Recherches Paul Pascal, UPR CNRS 8641, 115 Avenue du $\operatorname{Dr}$ A. Schweitzer, 33600 Pessac, France

$\dagger$ Electronic supplementary information (ESI) available: Geometries, equilibrium energies with the zero-point corrections, low frequencies and Cartesian coordinates for the optimized structures of TTF-SMe, $\mathbf{1}^{\prime} s$-trans, $\mathbf{1}^{\prime} s$-cis, $\mathbf{1}^{\prime+} \cdot s$-trans, $\mathbf{1}^{\prime+}{ }^{+} s$-cis, $\mathbf{1}^{\prime \prime}$ (including the summary for the PES calculation). See DOI: 10.1039/b701617d containing compounds, ${ }^{3}$ in the regulation of enzymatic functions, ${ }^{4}$ stabilization of folded protein structures, ${ }^{5}$ but also in supramolecular chemistry, as a tool for the crystal engineering. ${ }^{6}$ From a theoretical point of view, this type of interaction is most often described as a three center-four electron (3c-4e) interaction between a heteroatom $\mathrm{Y}(\mathrm{O}, \mathrm{N})$ lone pair orbital and a $\sigma^{*}(\mathrm{E}-\mathrm{C})(\mathrm{E}=\mathrm{S}, \mathrm{Se})$ orbital leading to a weak unsymmetrical hypervalent bond (Chart 1).

This feature was nicely evidenced, for example, in a series of anthraquinone and 9-methoxyanthracene bearing arylselanyl substituents at the 1,8-positions, thus showing intramolecular nonbonded $\mathrm{C}-\mathrm{Se}$. . O interactions, ${ }^{7}$ in (acylimino)thiadiazoline derivatives characterized by 1,5-nonbonded $\mathrm{S}$. . O interactions, ${ }^{3 b}$ or in 1,2,5-chalcogenadiazoles which form supramolecular associations thanks to intermolecular $\mathrm{N} \cdots \mathrm{E}$ (S, Se, Te) short contacts (Chart 2). ${ }^{6 c}$

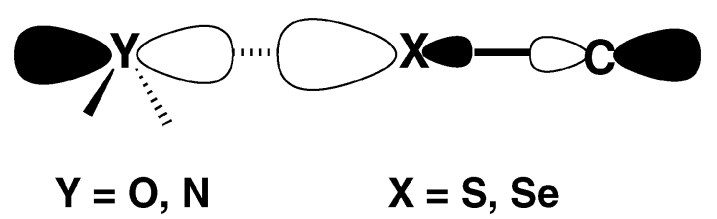

Chart 1 Schematic drawing of a $n \mathrm{p}-\sigma^{*} 3 \mathrm{c}-4 \mathrm{e}$ nonbonded interaction. 


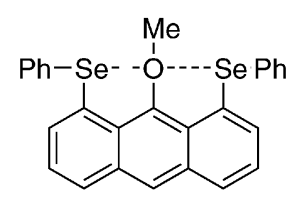

1,8-diselanyl-9-methoxyanthracene and related compounds; refs. 7-8<smiles>[R]c1nn([R5])c(=NC([R])O)s1</smiles>

(acylimino)thiadiazoline derivatives; ref. $3 b$

Chart 2 Selected examples of nonbonded interactions.

Moreover, this orbital $\mathrm{p}-\sigma^{*}$ model also describes at best chalcogen-chalcogen ( $\mathrm{S}, \mathrm{Se}, \mathrm{Te})$ nonbonded interactions, either intramolecular, as shown by Nakanishi et al. in 1,8substituted sulfanyl and selanyl naphthalene and anthracene derivatives, ${ }^{8}$ or intermolecular, as recently discussed by Gleiter and co-workers within a series of dimeric model systems of $\mathrm{Me}_{2} \mathrm{X} \cdots \mathrm{XMeZ}$ type $\left(\mathrm{X}=\mathrm{O}, \mathrm{S}, \mathrm{Se}, \mathrm{Te} ; \mathrm{Z}=\mathrm{Me}, \mathrm{C}_{2} \mathrm{H}, \mathrm{CN}\right) .{ }^{9}$ Interestingly, Raos et al. theoretically investigated a series of $\alpha, \alpha^{\prime}$-bithiophenes substituted in $\beta$ positions with $\mathrm{OCH}_{3}$ groups amongst others, and they found energy minima for planar conformations, very likely due to attracting 1,5 -nonbonded $\mathrm{S} \cdots \mathrm{O}$ interactions. ${ }^{10}$ They based their analysis on Bader's "atoms in molecules" (AIM) theory ${ }^{11}$ in order to identify and characterize the occurrence and strengths of these contacts, evidenced through the existence of "bond critical points" (BCP) and "ring critical points" (RCP). The results of Raos et al. are particularly interesting, since they highlight the role of the intramolecular nonbonded interactions, with respect to conjugation effects, in stabilizing planar conformations in $\alpha, \alpha^{\prime}$-bithiophenes, an important feature in the modulation of the electronic properties of thiophene based materials for electronics and optoelectronics. It is clear that in the field of conducting molecular materials, for which the solid-state properties are highly influenced by intra- and intermolecular contacts and orbital overlaps, thus allowing for tunable electron delocalization and activation within the solid, the $\mathrm{E} \cdots \mathrm{Y}(\mathrm{N}, \mathrm{O})$ nonbonded interactions might play a paramount role. This is all the more interesting since many electroactive valuable molecular precursors are chalcogen rich compounds. In this respect, prominent redox active organic sulfur containing donors are the tetrathiafulvalene (TTF) derivatives, ${ }^{12}$ a class of electroactive precursors extensively studied in the quest for molecular conductors and superconductors. ${ }^{13}$ To the best of our knowledge, TTF derivatives functionalized with groups susceptible to engage in intra-

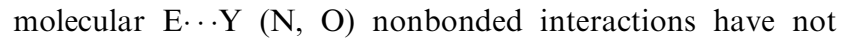
been synthesized on purpose so far.

We recently described the synthesis of chiral EDT-TTFoxazolines (EDT-TTF-OX) $\left(\right.$ EDT $=$ ethylenedithio) ${ }^{14}$ which provided the first complete series of molecular conductors based on chiral TTFs, including both $(R)$ and $(S)$ enantiomers, and the racemic mixture, bearing a methyloxazoline heterocycle. ${ }^{15}$ These donors, having $C_{1}$ symmetry, show conformational flexibility due to the relative orientation of the oxazoline with respect to the TTF mean plane, because of the free rotation around the $\mathrm{C}_{\mathrm{TTF}}-\mathrm{C}_{\mathrm{Ox}}$ single bond. This implies $a$ priori two possible energy minima corresponding to the $s$-trans and $s$-cis planar conformations (Chart 3).<smiles>[R]c1c([R])n2c([R])nn2[Y4]([H])n1[R]</smiles>

$\mathrm{X}=\mathrm{S}, \mathrm{Se}, \mathrm{Te}$

1,2,5-chalcogenadiazoles; ref. $6 c$<smiles>COC1=C(OC)c2ccc3c(c2)SC(=C1)S3</smiles>

$\alpha, \alpha^{\prime}$-bithiophenes;

ref. 10
In the solid-state structures of the neutral TTF-OX compounds, only the former was observed. On the contrary, in their radical cation salts the donor molecules adopt both conformations, very likely because of the small energy difference between them, probably even smaller in the oxidized form than in the neutral one. With respect to these conformational issues, we anticipated that the presence of a thioalkyl (-SR) group at the carbon atom ortho to the oxazoline ring would promote 1,5-type nonbonded intramolecular S $\cdots \mathrm{O}$ or $\mathrm{S} \cdots \mathrm{N}$ interactions, thus providing a complete planarization of both substituents, i.e. SR and oxazoline, with respect to the TTF plane (Chart 4).

Indeed, one can reasonably think that both interactions might occur, yet the $\mathrm{N} \cdots \mathrm{S}(\mathrm{Se})$ interaction seems to overcome the $\mathrm{O} \cdots \mathrm{S}(\mathrm{Se})$ one, as deduced from X-ray and spectroscopic data within a series of selanyl and sulfanyl oxazolines, ${ }^{16}$ although no theoretical calculations were performed by the authors in order to estimate their relative strengths. Note also that short intramolecular $\mathrm{O} \cdots \mathrm{S}$ contacts have been observed within crystalline structures of 2-thioxo-1,3-dithiole derivatives, ${ }^{17}$ which often serve as TTF precursors upon coupling reactions. Moreover, in the case of our targeted EDT-TTF(SMe)-oxazoline derivatives $\mathbf{1}$, the TTF oxidation state is likely to influence on the $\mathrm{S} \cdots \mathrm{N}$ vs. S...O balance as a fine tuning parameter.

We present in this report, first, the synthesis of the $( \pm)-,(R)$ and $(S)$-ethylenedithio-tetrathiafulvalene-thiomethyl-methyloxazolines (EDT-TTF-(SMe)-OX) 1 series along with their single-crystal $\mathrm{X}$-ray structures combined with theoretical

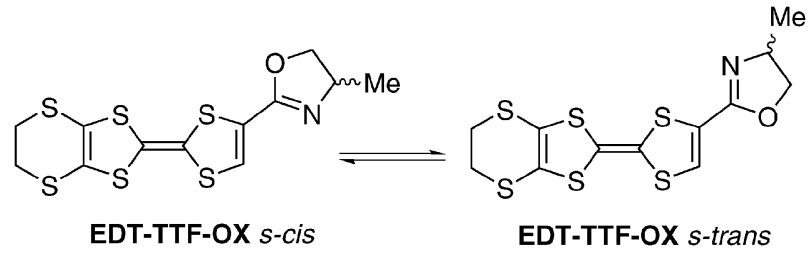

Chart 3 Conformations of racemic EDT-TTF-methyl-OX.

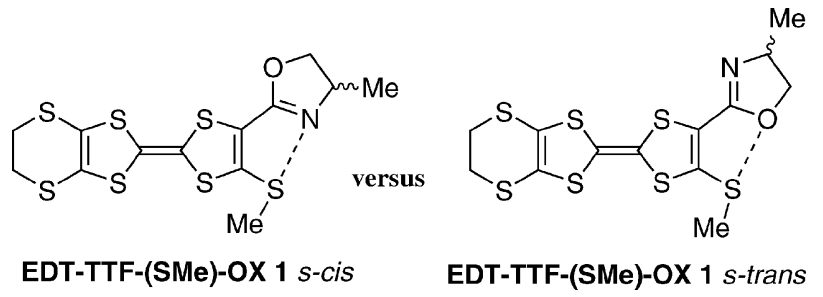

Chart 4 Possible conformations of EDT-TTF-SMe-OX. 


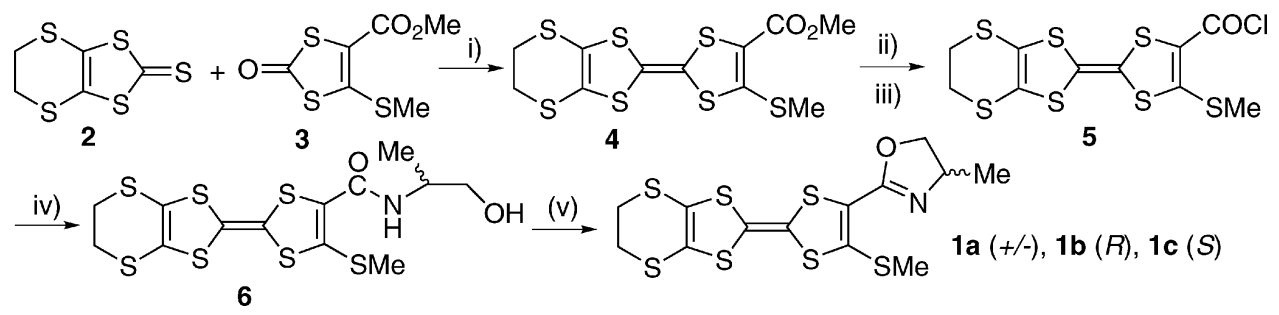

Scheme 1 Reagents and conditions: (i) $\mathrm{P}(\mathrm{OMe})_{3}, 4 \mathrm{~h}$ at $110^{\circ} \mathrm{C}$; (ii) $\mathrm{LiOH}$ to give the acid $\mathbf{4}^{\prime}$; (iii) $(\mathrm{COCl})_{2}$, THF, cat. Py; (iv) 2-amino-1-propanol $\left( \pm, R\right.$ or $S$ ), $\mathrm{NEt}_{3}, \mathrm{THF}, 12 \mathrm{~h}, \mathrm{RT}$; (v) $\mathrm{NEt}_{3}, \mathrm{THF}, \mathrm{MsCl}$ at $0{ }^{\circ} \mathrm{C}$, then $20 \mathrm{~h}$ at $50{ }^{\circ} \mathrm{C}$.

calculations, aiming at emphasizing the establishment of $\mathrm{S} \cdots \mathrm{N}$ or $\mathrm{S} \cdots \mathrm{O}$ nonbonded interactions. Then, we discuss the energy barrier between the corresponding planar conformations, estimated within a model compound. Finally we illustrate the same $\mathrm{S} \cdots \mathrm{N}$ or $\mathrm{S}$. O O nonbonded interactions in oxidized $\mathbf{1}$, for which a series of three radical cation salts with the ( \pm -1 1 donor and $\mathrm{Mo}_{6} \mathrm{Cl}_{14}$ dianion have been obtained, only by varying the solvent used in the electrocrystallization experiments. The correlation between the solid-state physical properties, single-crystal X-ray structures and theoretical calculations is also discussed in the case of these salts.

\section{Results and discussion}

\section{Synthesis and X-ray crystal structures of EDT-TTF-(SMe)-OX 1}

For the preparation of the chiral donors 1 we employed the classical cross coupling reaction in TTF chemistry, mediated by trimethyl phosphite, ${ }^{18}$ starting from the appropriate ethylenedithio-dithiolethione $\mathbf{2}$ and the functionalized dithiolone $\mathbf{3}$, readily obtained upon oxymercuration of the corresponding dithiolethione described in the literature. ${ }^{19}$

Then, hydrolysis under basic conditions followed by acylation with oxalyl chloride provides the acyl chloride 5. The reaction of the latter with the series of $( \pm)$-, $(R)$ - and $(S)$-2amino-1-propanol (alaninol) gives the $\beta$-hydroxyamides 6 , which are further treated with methane-sulfonyl chloride $(\mathrm{MsCl})$ to obtain the thiomethyl-oxazolines $\mathbf{1}$, in the same conditions as described for the simpler analogues (Scheme 1). ${ }^{14}$ Compounds 1 were characterized by ${ }^{1} \mathrm{H}$ and ${ }^{13} \mathrm{C} \mathrm{NMR}$, mass spectrometry and elemental analysis. Note the difference in melting points between the racemic oxazoline $1 \mathbf{a}\left(135{ }^{\circ} \mathrm{C}\right)$ and the enantiopure counterparts $\mathbf{1 b}, \mathbf{c}\left(155^{\circ} \mathrm{C}\right)$. Furthermore, suitable single-crystals for X-ray diffraction studies have been obtained for the three donors. The enantiopure oxazolines $\mathbf{1 b}$ $(R)$ and 1c $(S)$ are isostructural, crystallizing both in the orthorhombic system, non-centrosymmetric space group $P 2{ }_{1} 2_{1} 2_{1}$, with one independent molecule in the unit cell, in general position.

The most striking feature in the solid-state structures of $\mathbf{1 b}, \mathbf{c}$ is the establishment of a short intramolecular $\mathrm{O}(1) \cdots \mathrm{S}(7)$ contact at $2.87 \AA$ (Fig. 1). This distance is largely within the sum of the van der Waals radii of $\mathrm{S}$ and $\mathrm{O}$ atoms $(3.32 \AA),{ }^{20}$ clearly indicating the establishment of a O ‥S 1,5-type nonbonded interaction, also characterized by the collinearity of the $\mathrm{O}$...S-Me motif. The TTF-oxazoline conformation is thus of $s$-trans type and the overall geometry of the donor molecule is flat, only the $\mathrm{C}(8)$ carbon atom of the ethylenedithio bridge and the $\mathrm{C}(12)$ carbon atom on the oxazoline ring protruding out of the molecule mean plane. Folding angles along the S...S hinges amount to $2.4^{\circ}(\mathbf{1 b})$ and $1.4^{\circ}$ (1c) for $\mathrm{S}(1) \cdots \mathrm{S}(2)$, and to $5.5^{\circ}(\mathbf{1 b})$ and $6.2^{\circ}(\mathbf{1 c})$ for $\mathrm{S}(3) \cdots \mathrm{S}(4)$, whereas torsion angles of $6.1^{\circ}(\mathbf{1 b})$ and $5.7^{\circ}$ (1c) for $\mathrm{TTF}_{\text {mean }} \cdots \mathrm{OX}_{\text {mean }}$, and $4.4^{\circ}$ (1b) and $3.3^{\circ}$ (1c) for $\mathrm{TTF}_{\text {mean }} \cdots \mathrm{SMe}$ are observed. Intermolecular S...S distances within the stacking direction $a$ amount to 3.8-3.9 $\AA$. Interestingly, the quasi-planarity of the molecules allows for the engagement of the SMe sulfur atom in rather short $\mathrm{S}$. S $\mathrm{S}$ intermolecular contacts, thus suggesting its possible participation in the electron delocalization in corresponding radical cation salts. Intramolecular bond lengths are typical for a neutral TTF derivative (Table 1).

Moreover, the racemic 1a crystallizes in the orthorhombic system, centrosymmetric space group Pnma, with one

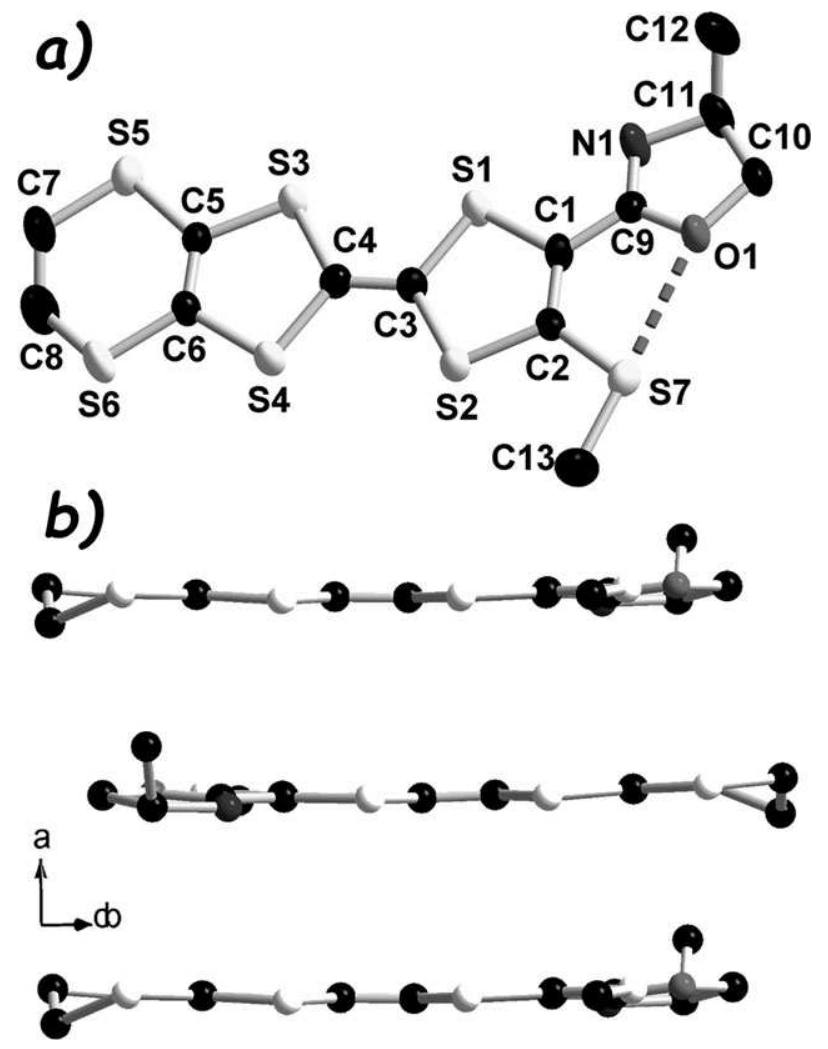

Fig. 1 ORTEP view of (S)-EDT-TTF-(SMe)-OX 1c (thermal ellipsoids set at $50 \%$ probability). Selected parameters: $\mathrm{O}(1) \cdots \mathrm{S}(7) 2.87 \AA$; angles $\left({ }^{\circ}\right)$ : $\mathrm{O}(1) \cdots \mathrm{S}(7)-\mathrm{Me}$ 176.2, folding $\left({ }^{\circ}\right)$ : $\mathrm{S}(1) \cdots \mathrm{S}(2) \quad 1.4$, $\mathrm{S}(3) \cdots \mathrm{S}(4) 6.2$, torsion $\left(^{\circ}\right)$ : TTF $\cdots$ OX 5.7, TTF ‥SMe 3.3. Hydrogen atoms have been omitted for clarity (a). Packing of molecules 1c along the $a$ direction (b). 
Table 1 Selected bond lengths $(\AA)$ in TTF moieties from X-ray crystal data

\begin{tabular}{|c|c|c|c|c|}
\hline & 1c & {$[\mathbf{1} \mathbf{a}]_{2} \mathrm{Mo}_{6} \mathrm{Cl}_{14}$} & {$[\mathbf{1} \mathbf{a}]_{4} \mathrm{Mo}_{6} \mathrm{Cl}_{14}$} & {$[\mathbf{1 a}]_{6} \mathrm{Mo}_{6} \mathrm{Cl}_{14}$} \\
\hline$a$ & $1.331(6)$ & $1.396(10)$ & $\begin{array}{l}1.383(8) \mathbf{A} \\
1.363(8) \mathbf{B}\end{array}$ & $\begin{array}{l}1.364(7) \mathbf{A} \\
1.323(8) \mathbf{B} \\
1.357(8) \mathbf{C}\end{array}$ \\
\hline$b$ & $1.758(4)$ & $1.716(7)$ & $\begin{array}{l}1.728(6) \mathbf{A} \\
1.744(6) \mathbf{B}\end{array}$ & $\begin{array}{l}1.739(6) \mathbf{A} \\
1.759(6) \mathbf{B} \\
1.737(6) \mathbf{C}\end{array}$ \\
\hline$c$ & $1.755(4)$ & $1.703(8)$ & $\begin{array}{l}1.728(6) \mathbf{A} \\
1.739(5) \mathbf{B}\end{array}$ & $\begin{array}{l}1.745(6) \mathbf{A} \\
1.765(6) \mathbf{B} \\
1.731(6) \mathbf{C}\end{array}$ \\
\hline$d$ & $1.751(5)$ & $1.724(7)$ & $\begin{array}{l}1.735(6) \mathbf{A} \\
1.739(5) \mathbf{B}\end{array}$ & $\begin{array}{l}1.748(6) \mathbf{A} \\
1.756(6) \mathbf{B} \\
1.741(6) \mathbf{C}\end{array}$ \\
\hline$e$ & $1.757(4)$ & $1.731(6)$ & $\begin{array}{l}1.721(6) \mathbf{A} \\
1.736(5) \mathbf{B}\end{array}$ & $\begin{array}{l}1.737(6) \mathbf{A} \\
1.746(6) \mathbf{B} \\
1.737(6) \mathbf{C}\end{array}$ \\
\hline
\end{tabular}

independent molecule in the unit cell, located on a mirror plane. This imposes a perfect planarity of the molecule, excepting the $\mathrm{C} 8$ carbon atom of the ethylenedithio bridge and the oxazoline methyl group $\mathrm{C} 12$, disordered with respect to the mirror plane. The fact that the molecule lies on a special position, which is a symmetry imposed constrain, combined with the small size of the crystals, leads to an overall medium quality of the structure, with some large thermal ellipsoids. The folding and torsion angles discussed in the case of the enantiopure counterparts fall all to $0^{\circ}$ (Fig. 2).

Both enantiomers are thus located on the same crystallographic site, adopting an $s$-trans conformation characterized by a rather short $\mathrm{O}(1) \cdots \mathrm{S}(7)$ intramolecular contact amounting to $2.95 \AA$, with a collinear $\mathrm{O} \cdots \mathrm{S}-\mathrm{Me}$ arrangement $\left(\mathrm{O} \cdots \mathrm{S}-\mathrm{Me}\right.$ angle equals $\left.177.4^{\circ}\right)$. Once again, this feature is reminiscent of a $\mathrm{O} \cdots \mathrm{S}$ 1,5-type nonbonded interaction.

Cyclic voltammetry measurements performed on thiomethyl-oxazolines 1a-c show that these compounds posses good electron donating properties. Indeed, typical two reversible single electron oxidation waves are observed, at potential values of $0.63\left(\mathrm{TTF}^{+} \bullet\right)$ and $1.11\left(\mathrm{TTF}^{2+}\right) \mathrm{V} v$ s. SCE, respectively, which is indicative of good stability of the corresponding radical cation species.

\section{Theoretical study on neutral TTF-OX}

The occurrence, within the series $\mathbf{1 a}-\mathbf{c}$, of $\mathrm{O} \cdots \mathrm{S}$ intramolecular short contacts is in sharp contrast with previous observa-

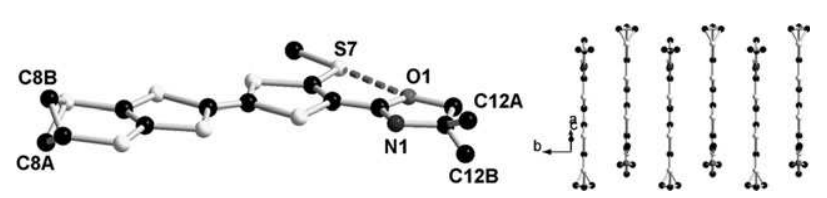

Fig. 2 Molecular structure of ( \pm )-EDT-TTF-(SMe)-OX 1a, located on a mirror plane perpendicular to $b$ axis. $\mathrm{C}(12 \mathrm{~A})$ corresponds to the $(R)$ enantiomer $(50 \%)$, while $\mathrm{C}(12 \mathrm{~B})$ to the $(S)$ one $(50 \%)$. Hydrogen atoms have been omitted for clarity (left). Packing of molecules 1a along the $b$ direction (right). tion of a $\mathrm{N}$...S nonbonded interaction in the case of a sulfanyl oxazoline, ${ }^{16 a}$ eventually suggesting that the energy difference between the two possible planar conformations, i.e. s-trans for the $\mathrm{O} \cdots \mathrm{S}$ interaction and $s$-cis for the $\mathrm{N} \cdots \mathrm{S}$ one, is likely to be small. Therefore, in order to evaluate both possible nonbonded interactions, we have undertaken a theoretical study at the DFT level, with the B3LYP functional and $6-31+\mathrm{G}^{*}$ basis set, on the model TTF-oxazoline $\mathbf{1}^{\prime}$, not containing a methyl group on the oxazoline ring (Fig. 3).

Starting from appropriate geometries of $\mathbf{1}^{\prime}$, both conformations have been optimized and converged to energy minima. The calculated equilibrium geometry for $\mathbf{1}^{\prime} s$-trans is in good agreement with the experimental structure of $\mathbf{1}$ as obtained from X-ray data (vide supra). Particularly interesting is the

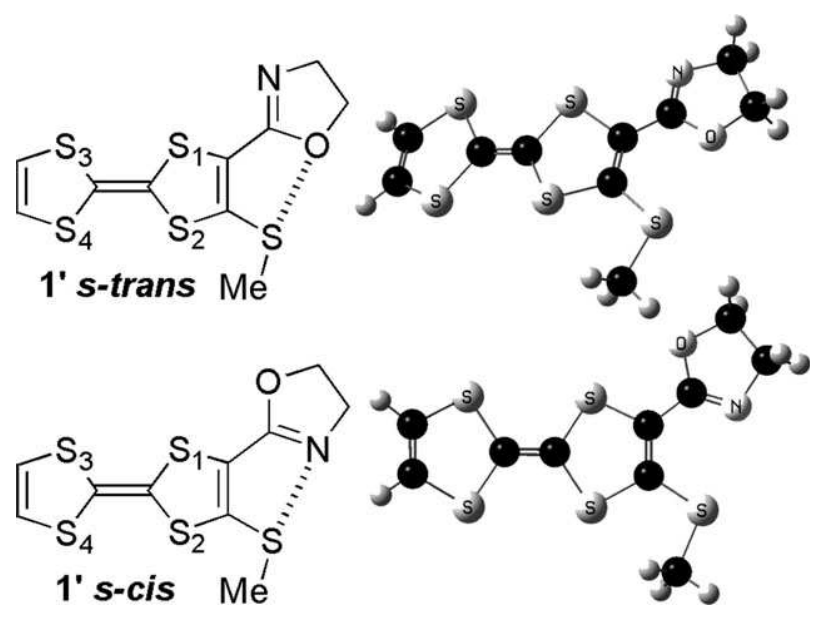

Fig. 3 DFT (B3LYP) geometry optimized structures of TTF-(SMe)OX 1's-trans (top) and $s$-cis (bottom). Selected calculated parameters: $s$-trans $\mathrm{O} \cdots \mathrm{S} 2.88 \AA$; angles $\left({ }^{\circ}\right)$ : $\mathrm{O} \cdots \mathrm{S}-\mathrm{Me} 167.5$, folding $\left({ }^{\circ}\right)$ : $\mathrm{S}(1) \cdots \mathrm{S}(2) \quad 11.3, \quad \mathrm{~S}(3) \cdots \mathrm{S}(4) \quad 7.3$, torsion $\left({ }^{\circ}\right)$ : TTF $\cdots \mathrm{OX} \quad 4.3$,

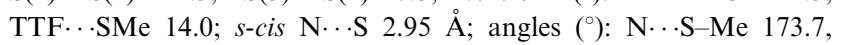
folding $\left({ }^{\circ}\right)$ : $\mathrm{S}(1) \cdots \mathrm{S}(2) 10.7, \mathrm{~S}(3) \cdots \mathrm{S}(4) 7.2$, torsion $\left(^{\circ}\right)$ : TTF $\cdots \mathrm{OX} 4.3$, TTF...SMe 7.3 . 
analysis of the folding and torsion angles, as well as the features of the $\mathrm{O} \cdots \mathrm{SMe}\left(\mathbf{1}^{\prime}\right.$ s-trans $)$ and $\mathrm{N} \cdots \mathrm{SMe}\left(\mathbf{1}^{\prime}\right.$ s-cis $)$ interactions. The overall geometry of both conformations is flat, with S...S, TTF ‥OX and TTF..SMe dihedral angles close to those experimentally observed. In the case of $\mathbf{1}^{\prime}$ s-trans, the short $\mathrm{O} \cdots \mathrm{S}$ distance of $2.88 \AA$ reproduces very well the experimental one $(2.87 \AA$ for 1c). Moreover, the oxygen atom aligns with the S-Me bond, thus suggesting the establishment of an $\mathrm{O} \cdots \mathrm{S}$ intramolecular nonbonded interaction. Also, in the case of $\mathbf{1}^{\prime} s$-cis, a $\mathrm{N}$...S nonbonded interaction is likely to occur, since the $\mathrm{N}$...S distance is as short as $2.95 \AA$, to compare with the sum of the van der Waals radii amounting to $3.35 \AA{ }^{20}$ and the $\mathrm{N}$ atom is collinear with the $\mathrm{S}-\mathrm{Me}$ bond. The energy difference between the optimized conformations is only of $0.26 \mathrm{kcal} \mathrm{mol}^{-1}$ in favor of the s-cis structure, therefore one can conclude that the crystallization of the only s-trans structure in the case of series $\mathbf{1 a}-\mathbf{c}$ is probably due to packing effects and other weak intermolecular interactions, not taken into account in the gas phase calculations. Another factor which could provide additional stabilization for the s-trans conformation over the s-cis one is the presence, in 1a-c, of a methyl group at the chiral C(11) carbon atom adjacent to the nitrogen atom, hence a source of steric hindrance likely to hamper the $\mathrm{N} \cdots \mathrm{S}$ contact.

In order to have additional characterization of these secondary-bonding interactions, we have undertaken the Bader's "atoms in molecules" (AIM) analysis ${ }^{11}$ of the electron density in the case of the model TTF-OX $\mathbf{1}^{\prime}$. Although subject to controversy between theoretical chemists, ${ }^{21}$ this theory was applied in various types of interactions between closed-shell atoms, such as hydrogen bonding, ${ }^{22}$ van der Waals interactions, ${ }^{23}$ or intramolecular chalcogen-chalcogen interactions. ${ }^{8 e, 24}$ A very useful summary of the AIM theory, containing the relevant items highlighting the characteristics of nonbonded interactions, can be found in the report of Raos et al. describing conformational states and stabilization due to nonbonded interactions in substituted bithiophenes. ${ }^{10}$ The goal of our approach was to identify the "bond critical point" (BCP), characterized by a certain value of the electron density $\left(\rho_{\mathrm{B}}\right)$, associated to the supposed $\mathrm{X} \cdots \mathrm{S}(\mathrm{X}=\mathrm{N}, \mathrm{O})$ nonbonded interaction. The magnitude of the BCP electron density correlates with the interaction strength, ${ }^{25}$ such as it was shown in $\mathrm{H}$-bonded complexes. ${ }^{22}$ More interesting for our study is the value of $\rho_{\mathrm{B}}=7.7 \times 10^{-3}$ of the electron density at the BCP for the $\mathrm{S} \cdots \mathrm{O}$ intermolecular interaction in the supramolecular complex $\left(\mathrm{SO}_{2}\right)_{2}{ }^{23}$ Another magnitude associated to a $\mathrm{BCP}$ is the Laplacian $\nabla^{2} \rho_{\mathrm{B}}$ of the density, which is negative for a shared-electron covalent bond and positive for a closed-shell interaction. ${ }^{11,23}$ Values of $\nabla^{2} \rho_{\mathrm{B}}$ for hydrogen bonds range between $2.4 \times 10^{-2}$ and $14 \times 10^{-2}$, whereas for the $\mathrm{S} \cdots \mathrm{O}$ interaction in $\left(\mathrm{SO}_{2}\right)_{2}$ a value of $3.1 \times 10^{-2}$ has been determined. ${ }^{23}$ The analysis of these two parameters, i.e. $\rho_{\mathrm{B}}$ and $\nabla^{2} \rho_{\mathrm{B}}$, along with the corresponding contraction ratio $C_{\mathrm{XS}}$ with respect to the sum of the van der Waals radii of $\mathrm{X}$ and $\mathrm{S}$ (Table 2), undoubtedly indicate the establishment of rather strong $\mathrm{O} \cdots \mathrm{S}$ and $\mathrm{N} \cdots \mathrm{S}$ nonbonded interactions in $\mathbf{1}^{\prime}$ s-trans and $\mathbf{1}^{\prime} s$-cis, respectively.

The characteristics for the $\mathrm{O} \cdots \mathrm{S}$ interaction compare very well with those obtained by Raos et al. in their study, ${ }^{10}$
Table 2 AIM analysis on B3LYP $/ 6-31+\mathrm{G}^{*}$ electron densities: selected properties at the BCPs for the X $\cdots \mathrm{S}$ nonbonded interactions ${ }^{a}$

\begin{tabular}{llllll}
\hline TTF-(SMe)-OX & $\mathrm{X} \cdots \mathrm{S}$ & $D_{\mathrm{XS}}$ & $C_{\mathrm{XS}}$ & $10^{2} \rho_{\mathrm{B}}$ & $10^{2} \nabla^{2} \rho_{\mathrm{B}}$ \\
\hline $\mathbf{1}^{\prime}$ s-trans & $\mathrm{O} \cdots \mathrm{S}$ & 2.88 & 0.87 & 1.40 & 5.01 \\
$\mathbf{1}^{\prime+\bullet}$ s-trans & $\mathrm{O} \cdots \mathrm{S}$ & 2.90 & 0.87 & 1.34 & 4.81 \\
$\mathbf{1}^{\prime}$ s-cis & $\mathrm{N} \cdots \mathrm{S}$ & 2.95 & 0.88 & 1.42 & 4.70 \\
$\mathbf{1}^{\prime} \cdot{ }^{\prime}$ s-cis & $\mathrm{N} \cdots \mathrm{S}$ & 2.94 & 0.88 & 1.46 & 4.77
\end{tabular}

${ }^{a} D_{\mathrm{XS}}=\mathrm{X} \cdots \mathrm{S}$ distance $(\AA) ; C_{\mathrm{XS}}=D_{\mathrm{XS}} /(\mathrm{RX}+\mathrm{RS})$ contraction ratio with respect to the sum of the van der Waals radii of $\mathrm{X}$ and $\mathrm{S}^{20} ; \rho_{\mathrm{B}}=$ electron density at the BCP (au); $\nabla^{2} \rho_{\mathrm{B}}=$ Laplacian at the BCP (au).

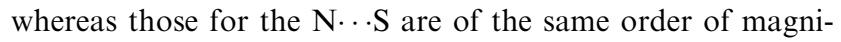
tude, both falling in the range of moderate strong hydrogen bonds. ${ }^{22,23}$ Note that the values of the ellipticity (see ESI $\dagger$ ) range between 0.13 and 0.17 , indicating a certain anisotropy of the charge distribution. Moreover, one can ask the question whether this $\mathrm{X} \cdots \mathrm{S}$ interaction, supposed of $n \mathrm{p}_{\mathrm{X}}-\sigma^{*} \mathrm{~s}_{-\mathrm{C}}$ type, can be retraced from its contribution to certain molecular orbitals.

Let us examine first a couple of molecular orbitals of $\mathbf{1}^{\prime}$ s-trans (Fig. 4). As can be observed in Fig. 4, the HOMO of the molecule is clearly of TTF $\pi$ type, with some non-negligible contribution from the sulfur atom of the SMe group and also from the nitrogen atom. This feature suggests that in the corresponding radical cation salts some electronic density is likely to be delocalized over these atoms. Interestingly, one can find the signature of the $\mathrm{O} \cdots \mathrm{S}$ interaction in lower occupied orbitals, such as HOMO-13 in which a bonding combination between an oxygen lone pair and the $\sigma^{*}{ }_{\mathrm{S}-\mathrm{C}}$ is definitely observed, thus proving that the description of the $\mathrm{O} \cdots \mathrm{S}$ weakly-bonding interaction as a $3 \mathrm{c}-4 \mathrm{e}$ model is adequate. Note, however, that a small part of this molecular orbital is due to a bonding combination between the $2 \mathrm{p}_{y}(\mathrm{C})$ and $1 \mathrm{~s}(\mathrm{H})$ orbitals. Moreover, the molecular orbital HOMO-13, containing a likely $n \mathrm{p}_{\mathrm{O}}-\sigma^{*} \mathrm{~S}_{-\mathrm{C}}$ combination, is deep in energy, and thus accounts at best for a bond description. The situation is only slightly different in the case of $\mathbf{1}^{\prime}$ s-cis in the sense that the HOMO is also of TTF $\pi$ type with coefficients on nitrogen and sulfur SMe atoms, while a bonding $2 \mathrm{p}_{z}(\mathrm{~N})-3 \mathrm{p}_{z}(\mathrm{~S})$ combination can be distinguished in the $\pi$ type HOMO-1, an original feature within this type of nonbonded interactions, suggesting that $\pi$ interactions are very likely involved in the establishment of a short $\mathrm{N}$...S contact (Fig. 5). Indeed, theoretical studies on a series of chalcogen containing diazenes undoubtedly demonstrated the important role of the $\pi$ type orbital interactions in the stabilization of intramolecular E $\cdots \mathrm{N}$ contacts. ${ }^{26} \mathrm{It}$ is thus clear that in the case of our TTF-SMe-OX the stabilization of

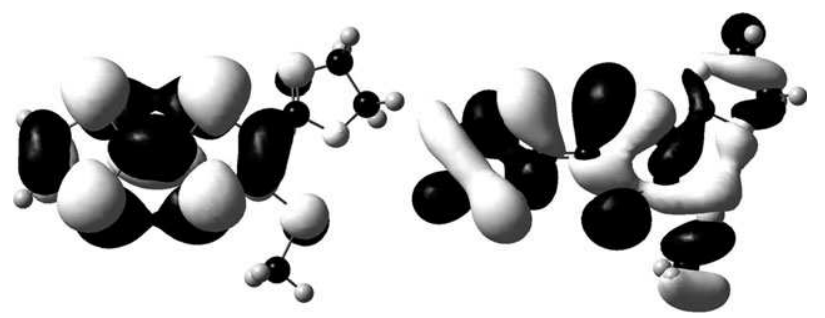

Fig. 4 Molecular orbitals of $\mathbf{1}^{\prime}$ s-trans: HOMO (left), HOMO-13 (right). 


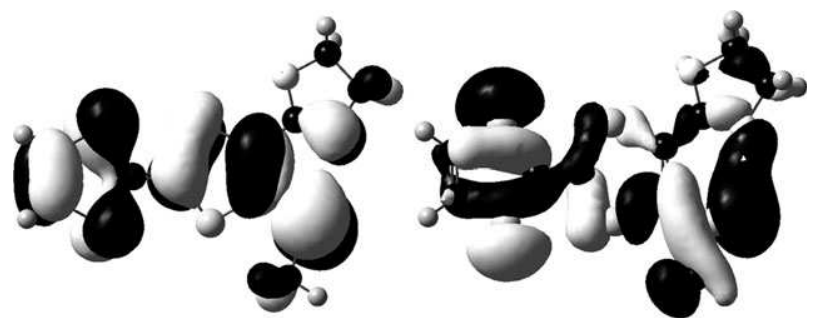

Fig. 5 Molecular orbitals of $\mathbf{1}^{\prime}$ s-cis: HOMO-1 (left), HOMO-9 (right).

planar structures, be they s-cis or s-trans, is largely favored also by $\pi$ interactions such as $\mathrm{p}(\mathrm{S})-\pi(\mathrm{C}=\mathrm{C})$ and $\pi(\mathrm{C}=\mathrm{C})-\pi(\mathrm{C}=\mathrm{N})$. However, the quantitative evaluation of the $\pi$ contribution, or other forces such as the Pauli repulsion between lone pairs, is beyond the scope of our present study.

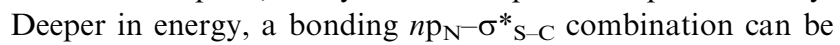
observed in the HOMO-9 molecular orbital, also containing a very small $2 \mathrm{p}_{y}(\mathrm{C})-1 \mathrm{~s}(\mathrm{H})$ bonding contribution.

This demonstrates once again that the $3 \mathrm{c}-4 \mathrm{e}$ model accurately describes also the $\mathrm{N}$...S nonbonded interaction in our case.

\section{Barrier energy between s-cis and s-trans conformations}

As discussed above, the two optimized conformations are isoenergetic. Nevertheless, the question concerning the required energy barrier corresponding to the equilibrium between the two forms might arise. In order to address this point we performed a relaxed scan potential energy surface (PES) calculation at DFT level with the B3LYP/6-31+ G* functional and basis set, on a simpler model, namely the achiral cis(SMe)-oxazoline-ethene $\mathbf{1}^{\prime \prime}$. We started our calculation from the optimized geometry of the planar s-cis conformation, characterized by a short $\mathrm{N}$. S S distance of $3.01 \AA$, albeit longer than in the model $\mathbf{1}^{\prime}$, and then we increased stepwisely the value of the torsion angle $\mathrm{C}=\mathrm{C} \cdots \mathrm{OX}(D 1)$ by increments of $15^{\circ}$. At each step of this rotational process all the geometric parameters were optimized with respect to the fixed value of $D 1$. As expected, when the angle $D 1$ reached the value of $180^{\circ}$, the $s$-trans conformation of $\mathbf{1}^{\prime \prime}$ was obtained within a planar geometry, characterized by a short O ...S distance of $2.93 \AA$. Once again, as in the case of $\mathbf{1}^{\prime}$, the optimized s-cis conformation was only slightly more stable, by $0.36 \mathrm{kcal} \mathrm{mol}^{-1}$, than the $s$-trans one. Interestingly, the SMe group has the tendency to follow the rotation of the oxazoline, thus keeping a short $\mathrm{N}$...S distance as much as possible. However, this distance steadily increases with $D 1$, to overcome the sum of the van der Waals radii ( $3.35 \AA$ ) for a value of $D 1$ between $45^{\circ}$ (N . . S 3.23 $\AA$ ) and $60^{\circ}(\mathrm{N} \cdots \mathrm{S} 3.40 \AA$ ). The relative energy of the different conformations reaches a maximum at $7.1 \mathrm{kcal} \mathrm{mol}^{-1}$, corresponding to a $D 1$ value of $90^{\circ}$, and a value of $22.7^{\circ}$ for the torsion angle $\mathrm{C}=\mathrm{C} \cdots \mathrm{SMe}$. The latter falls back to $0^{\circ}$ in the s-trans conformation (Fig. 6).

Obviously, an energy barrier of around $7 \mathrm{kcal} \mathrm{mol}^{-1}$, which can be taken as an evaluation of the $\mathrm{N} \cdots \mathrm{S}$ or $\mathrm{O} \cdots \mathrm{S}$ interaction strength, definitely allows for a free rotation at room temperature of the oxazoline ring and SMe group with respect to the TTF mean plane, be it in the model $\mathbf{1}^{\prime}$ or in the real system $\mathbf{1}$.

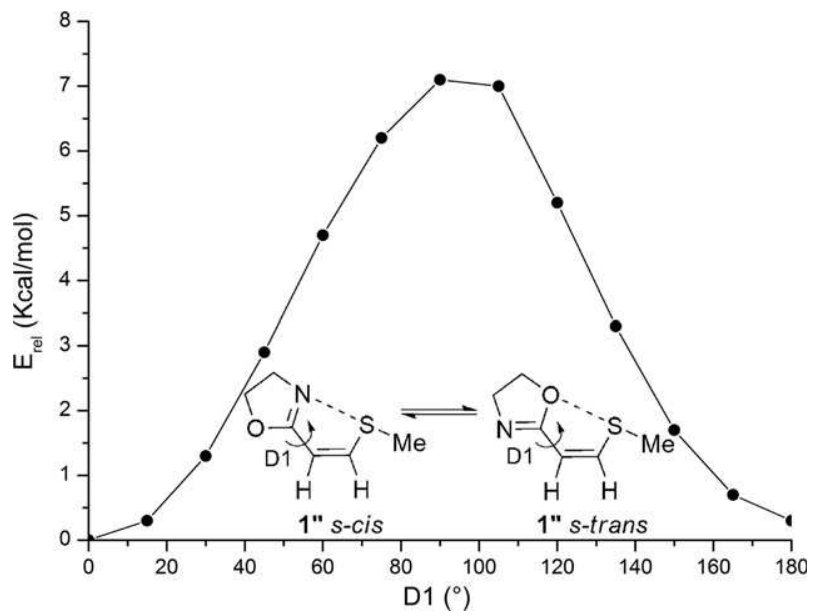

Fig. 6 DFT/B3LYP relaxed potential energy surface (PES) calculation on the model compound $\mathbf{1}^{\prime \prime}$, with respect to the dihedral angle $\mathrm{C}=\mathrm{C} \cdots \mathrm{OX}(D 1)$. The energy barrier amounts at $7.1 \mathrm{kcal} \mathrm{mol}^{-1}$ for $D 1=90^{\circ}$.

Nevertheless, these interactions are very likely strong enough to favor in the solid state the crystallization of the planar conformations s-trans or $s$-cis. Low-temperature solution ${ }^{1} \mathrm{H}$ NMR measurements, down to $223 \mathrm{~K}$, temperature at which the compound precipitated, did not allow for the observation of the two conformations in equilibrium. However, this is not surprising when considering the low value of the energy barrier. Note that the geometry optimization of the simple TTF-SMe derivative, not containing the oxazoline ring, at the same level of theory, provided a minimum of energy for a conformation with a torsion angle TTF...SMe amounting to $65^{\circ}$, well beyond a planar structure (ESI $\dagger$ ).

\section{Theoretical study on TTF-OX radical cations}

In order to evaluate to what extent the TTF oxidation state influences on these $\mathrm{N} \cdots \mathrm{S}$ and $\mathrm{O} \cdots \mathrm{S}$ weakly-bonding interactions, we have performed DFT/UB3LYP calculations on the corresponding radical cation species of $\mathbf{1}^{\prime}$ s-trans and $\mathbf{1}^{\prime}$ s-cis. Both conformations are energy minima, within fully planar geometry for each, as indicated by the values of $0^{\circ}$ for the S...S folding angles and TTF...OX and TTF...SMe torsion angles. The planarity of the TTF moiety is a recurrent feature in radical cation species, ${ }^{12}$ whereas the mutual planarity of the oxazoline ring and $\mathrm{SMe}$ group is a likely consequence of $\mathrm{N} \cdots \mathrm{S}$ or $\mathrm{O} \cdots \mathrm{S}$ nonbonded interactions. Indeed, as in the case of neutral $\mathbf{1}^{\prime}$, the same geometric, orbital and AIM analysis can be undertaken for $\mathbf{1}^{\prime+} \bullet$ in order to assess the occurrence of these interactions and to correlate the theoretical results with $\mathrm{X}$-ray data on radical cation salts of $\mathbf{1}$. Thus, in the optimized structure of $\mathbf{1}^{\prime+} \cdot s$-trans (Fig. 7) the O $\cdots$ S distance amounts at $2.90 \AA$, with an almost perfect O . SMe alignment (angle at $\left.176.9^{\circ}\right)$. The SOMO of $\mathbf{1}^{\prime+} \cdot s$-trans, suggesting a sizeable electron delocalization over the SMe group and $\mathrm{N}$ atom, is also shown in Fig. 7, along with a molecular orbital (HOMO-10) containing a $n \mathrm{p}_{\mathrm{O}}-\sigma^{*}{ }_{\mathrm{S}-\mathrm{C}}$ character, although some bonding $2 \mathrm{p}_{y}(\mathrm{C})-1 \mathrm{~s}(\mathrm{H})$ is also observed.

On the other hand, the $\mathrm{N} \cdots \mathrm{S}$ distance in the optimized structure of $\mathbf{1}^{\prime+} \cdot s$-cis reaches $2.94 \AA$, while the $\mathrm{N}$. . SMe motif 

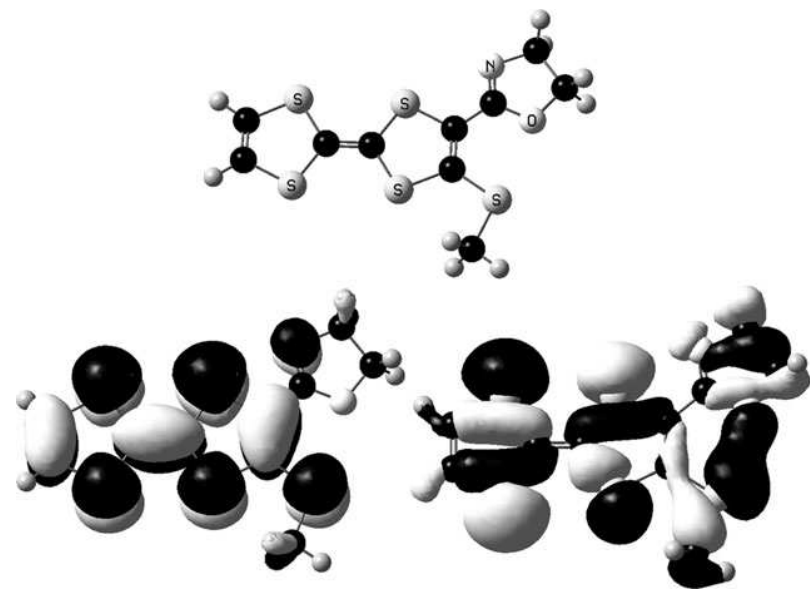

Fig. 7 Optimized structure of $\mathbf{1}^{\prime+} \cdot s$-trans (top), SOMO (bottom left) and HOMO-10 (bottom right).

is also linear with the corresponding angle at $176.8^{\circ}$ (Fig. 8). Representative molecular orbitals, such as the SOMO, suggesting the involvement of the SMe group and oxazoline ring in the electron delocalization, and the HOMO-7, illustrating the $n \mathrm{p}_{\mathrm{N}}-\sigma^{*}{ }_{\mathrm{S}-\mathrm{C}}$ overlap, are shown in the same figure.

The AIM analysis (vide supra) allowed to detect a BCP (bond critical point) associated to the $\mathrm{O} \cdots \mathrm{S}$ interaction. Selected AIM parameters, i.e. $\rho_{\mathrm{B}}$ (electron density at the bond critical point) and $\nabla^{2} \rho_{\mathrm{B}}$ (Laplacian of $\rho_{\mathrm{B}}$ ), for $\mathbf{1}^{\prime+} \cdot{ }_{s \text {-trans are }}$ listed in Table 2. Their magnitudes eventually suggest, when compared to those of neutral $\mathbf{1}^{\prime}$ s-trans, that the interaction weakens at some extent upon oxidation of TTF. On the contrary, one could say that the $\mathrm{N} \cdots \mathrm{S}$ interaction somewhat strengthens in $\mathbf{1}^{\prime+} \cdot s$-cis when compared with $\mathbf{1}^{\prime} s$-cis with respect to the values of $\rho_{\mathrm{B}}$ and $\nabla^{2} \rho_{\mathrm{B}}$, yet in both radical cation conformations the $\mathrm{X} \cdots \mathrm{S}$ nonbonded interactions are still in the range of moderate strong hydrogen bonds. ${ }^{22,23}$ As a matter of fact, the calculated energy difference $\Delta E=E_{\mathbf{1}^{\prime}+} \cdot{ }_{\text {s-trans }}-$ $E_{\mathbf{1}^{\prime}+} \cdot{ }_{\text {s-cis }}$ of $0.63 \mathrm{kcal} \mathrm{mol}^{-1}$ between the two optimized conformations, although still very small, shows the same tendency as the AIM parameters towards a slight stabilization

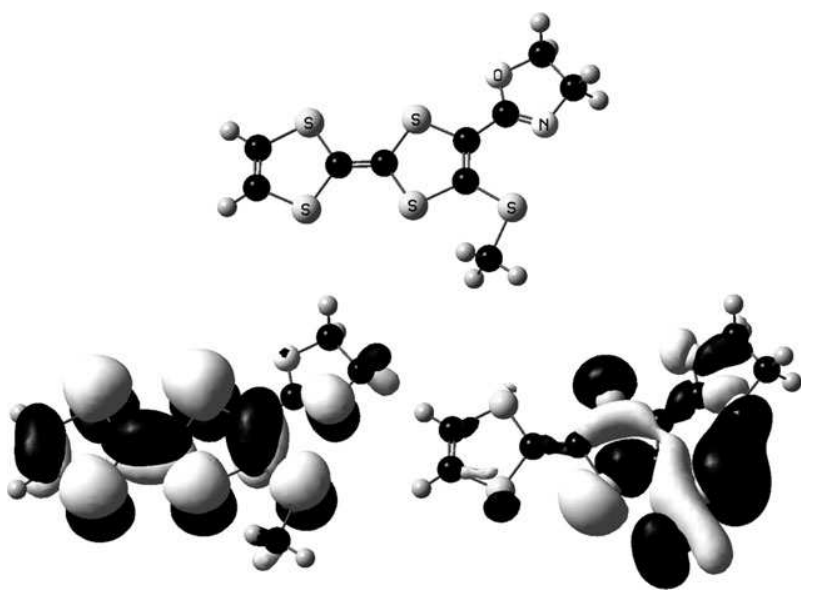

Fig. 8 Optimized structure of $\mathbf{1}^{\prime+} \cdot s$-cis (top), SOMO (bottom left) and HOMO-7 (bottom right). of the $s$-cis conformation with respect to the $s$-trans one. Then the question arises whether this trend eventually correlates with experimental observations.

\section{A 2:1 radical cation salt of 1 a with the $\mathrm{Mo}_{6} \mathrm{Cl}_{14}{ }^{2-}$ dianion}

One of the main goals in TTF chemistry is the synthesis of radical cation salts exhibiting interesting physical properties, such as electronic conductivity and/or magnetism in the solid state. ${ }^{13}$ Accordingly, we focused next on electrocrystallization experiments with the racemic donor 1a, which provided an original series of three radical cation salts with the same dianion $\mathrm{Mo}_{6} \mathrm{Cl}_{14}{ }^{2-}$, but different stoichiometries tuned only by changing the solvent in the electrocrystallization cell. The first salt we describe herein was obtained upon oxidation of $\mathbf{1 a}$ in $\mathrm{CH}_{2} \mathrm{Cl}_{2}$ in the presence of $\left[(n-\mathrm{Bu})_{4} \mathrm{~N}\right]_{2}\left[\mathrm{Mo}_{6} \mathrm{Cl}_{14}\right]$ as supporting electrolyte. The $\mathrm{X}$-ray diffraction analysis on small brown crystalline blocks revealed a stoichiometry of $2: 1$, therefore the salt can be formulated as $[\mathbf{1 a}]_{2}\left[\mathrm{Mo}_{6} \mathrm{Cl}_{14}\right]$, hence full oxidation of TTF. The compound crystallizes in the triclinic system, space group $P \overline{1}$, with one independent enantiomer of EDTTTF-(SMe)-OX in general position and a dianionic $\mathrm{Mo}_{6} \mathrm{Cl}_{14}{ }^{2-}$ cluster located on an inversion center in the unit cell. The opposite enantiomer of EDT-TTF-(SMe)-OX is generated through the inversion center (Fig. 9).

Selected bond lengths for the TTF moiety, in good agreement with those for a radical cation, i.e. lengthening of the central $\mathrm{C}=\mathrm{C}$ bond and shortening of the $\mathrm{C}-\mathrm{S}$ bonds when compared to the neutral species, ${ }^{13}$ are given in Table 1 . The folding angles about the $\mathrm{S}(1) \cdots \mathrm{S}(2)$ and $\mathrm{S}(3) \cdots \mathrm{S}(4)$ hinges are $0^{\circ}$, whereas only slight distortions TTF..OX $\left(2.0^{\circ}\right)$ and TTF...SMe $\left(4.7^{\circ}\right)$ are observed, thus leading to an overall planar geometry of the TTF-(SMe)-OX fragment. Once again, one can distinguish an $\mathrm{O} \cdots \mathrm{S}$ nonbonded interaction, characterized by a short $\mathrm{O} \cdots \mathrm{S}$ distance of $2.97 \AA$ and a linear $\mathrm{O}$...SMe motif. The radical cations of the donor organize in slightly slipped centrosymmetric dimers, with rather short intermolecular S...S distances of about $3.45 \AA$, which is likely to favor a strong coupling of the radicals. This behavior is most often encountered within TTF salts containing fully oxidized donors. Moreover, S...S interdimer distances are quite longer (3.85-3.95 $\AA$ ), above the sum of the van der Waals radii $(3.70 \AA) .{ }^{20}$ The packing diagram of the compound

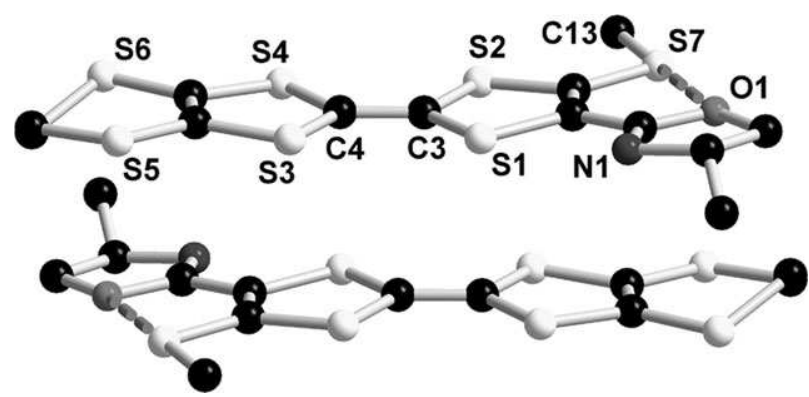

Fig. 9 Centrosymmetric dimer in the structure of $[\mathbf{1 a}]_{2}\left[\mathrm{Mo}_{6} \mathrm{Cl}_{14}\right]$. Selected parameters: $\mathrm{O}(1) \cdots \mathrm{S}(7) 2.97 \AA$; angles $\left({ }^{\circ}\right)$ : $\mathrm{O}(1) \cdots \mathrm{S}(7)-\mathrm{Me}$ 173.9; intermolecular distances: $\mathrm{S}(1) \cdots \mathrm{S}(4)^{\prime}(-x, 1-y, 1-z) 3.43$, $\mathrm{S}(3) \cdots \mathrm{S}(2)^{\prime}(-x, 1-y, 1-z) 3.46, \mathrm{~S}(5) \cdots \mathrm{S}(7)^{\prime}(-x, 1-y, 1-z)$ 3.74. Hydrogen atoms have been omitted for clarity. 


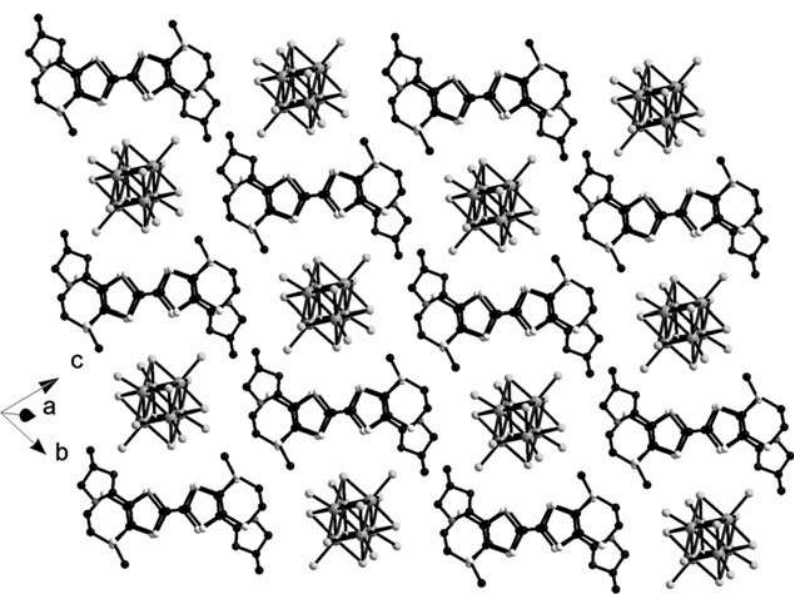

Fig. 10 Packing diagram of $[\mathbf{1} \mathbf{a}]_{2}\left[\mathrm{Mo}_{6} \mathrm{Cl}_{14}\right]$.

shows no clear organic-inorganic segregation, with formation of chains of TTF dimers along the $a$ direction (Fig. 10).

\section{A 6:1 radical cation salt of 1 a with the $\mathrm{Mo}_{6} \mathrm{Cl}_{14}{ }^{2-}$ dianion}

A completely different salt was obtained when 1a was electrocrystallized in acetonitrile with the same supporting electrolyte. This time, large thick black plates were harvested on the electrode, and their single-crystal $\mathrm{X}$-ray analysis allowed to formulate the salt as $[\mathbf{1 a}]_{6}\left[\mathrm{Mo}_{6} \mathrm{Cl}_{14}\right] \cdot 2 \mathrm{MeCN}$, that is six molecule of donors for a dianion, which represents a most interesting stoichiometry, since it implies, a priori, a mean charge of +0.33 on each donor. However, the compound crystallizes in the triclinic system, space group $P \overline{1}$, with three independent TTF molecules in general positions (Fig. 11), one acetonitrile molecule also in general position and a cluster $\mathrm{Mo}_{6} \mathrm{Cl}_{14}{ }^{2-}$ located on an inversion center in the unit cell.

The in depth analysis of intramolecular bond lengths (Table 1) for the three molecules $\mathbf{A}, \mathbf{B}$ and $\mathbf{C}$ and comparison with data for neutral $\mathbf{1}$ and radical cation salt $[\mathbf{1}]_{2}\left[\mathrm{Mo}_{6} \mathrm{Cl}_{14}\right]$, previously described, unambiguously suggest that molecules $\mathbf{A}$ and $\mathbf{C}$, characterized by intermediate values for $\mathbf{C}=\mathrm{C}$ and

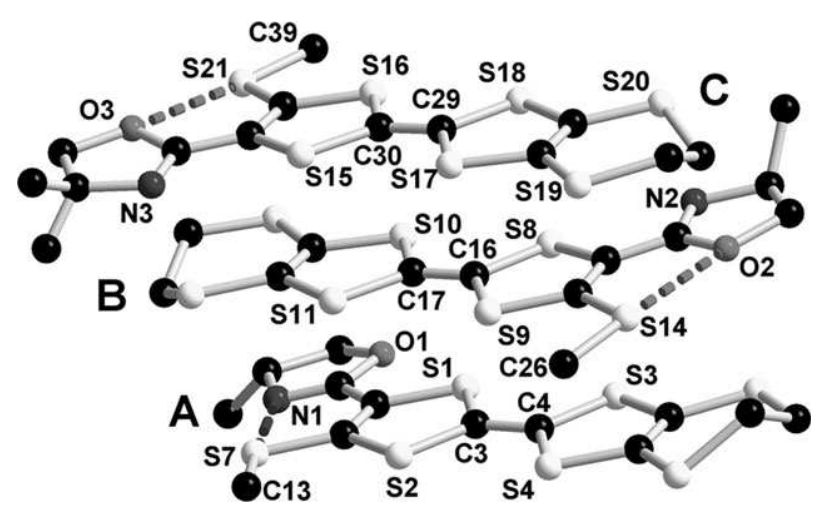

Fig. 11 View of the three independent TTF molecules in the structure of $[\mathbf{1 a}]_{6}\left[\mathrm{Mo}_{6} \mathrm{Cl}_{14}\right]$. Selected parameters: A: $\mathrm{N}(1) \cdots \mathrm{S}(7) 2.94 \AA$, $\mathrm{N}(1) \cdots \mathrm{S}(7)-\mathrm{Me} 177.1^{\circ}$; B: $\mathrm{O}(2) \cdots \mathrm{S}(14) 2.93 \AA$, O(2) $\cdots \mathrm{S}(14)-\mathrm{Me}$ $176.5^{\circ}$; C: $\mathrm{O}(3) \cdots \mathrm{S}(21) 2.87 \AA$ A, $\mathrm{O}(3) \cdots \mathrm{S}(21)-\mathrm{Me} 174.5^{\circ}$. Disorder on the ethylene bridge of molecule $\mathbf{B}$ is not represented. Hydrogen atoms have been omitted for clarity.
$\mathrm{C}-\mathrm{S}$ bonds, are very likely in mixed valence oxidation state with a mean charge $\rho=+0.5$, while molecules $\mathbf{B}$ seem to remain neutral. Therefore, at this stage, we can reasonably reformulate the salt as $\left[(\mathbf{A})_{2}{ }^{+}(\mathbf{B})_{2}{ }^{0}(\mathbf{C})_{2}{ }^{+}\right]\left[\mathrm{Mo}_{6} \mathrm{Cl}_{14}\right]^{2-}$. Interestingly, for the first time in this series, crystallization as s-cis conformation is observed for the molecule $\mathbf{A}$, hence the establishment of an N..S nonbonded interaction, with a short $\mathrm{N}$...S distance of $2.94 \AA$, to be compared with the calculated

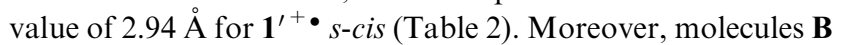
and $\mathbf{C}$ crystallize as s-trans conformations, characterized by short $\mathrm{O} \cdots \mathrm{S}$ distances (Fig. 11). Note the overall flat geometry of the three donors, with TTF...OX and TTF...SMe torsion angles close to $0^{\circ}$, and the occupational disorder at the chiral carbon atom on the oxazoline ring of molecules $\mathbf{C}$, as a consequence of the statistical presence of both enantiomers on the same crystallographic site. The observation of both types of nonbonded interactions within the crystalline structure of this salt eventually confirms the predictions of the theoretical calculations concerning the relative stability of the two planar conformations in radical cation salts.

Contrary to the previously discussed fully oxidized salt, in $[1 \mathrm{a}]_{6}\left[\mathrm{Mo}_{6} \mathrm{Cl}_{14}\right]$ there is clearly an organic-inorganic segregation along the $b$ direction, with interacting organic donors organized in parallel columns forming slabs in the $a c$ plane, and molecules of solvent included in the anionic slabs (Fig. 12). Thus, TTF molecules stack along $c$, with a multitude of short intermolecular S..S distances (Fig. 13). Moreover, one can distinguish also some lateral S...S contacts along $a$, between $\mathbf{B}$ and $\mathbf{C}$ molecules, for example. In order to evaluate quantitatively the strength of the HOMO-HOMO interactions between the donors, which is related to the extent of the electron delocalization, accounting for conducting and/or magnetic properties within the solid, we performed extended Hückel calculations to determine the intermolecular

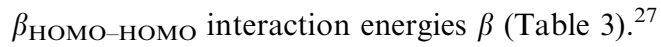

Then, tight-binding calculations led to the band structure diagram shown in Fig. 14. According to the stoichiometry of the salt, two holes have to be placed in the upper pair of bands, yet, the flatness of the bands indicates undoubtedly that the

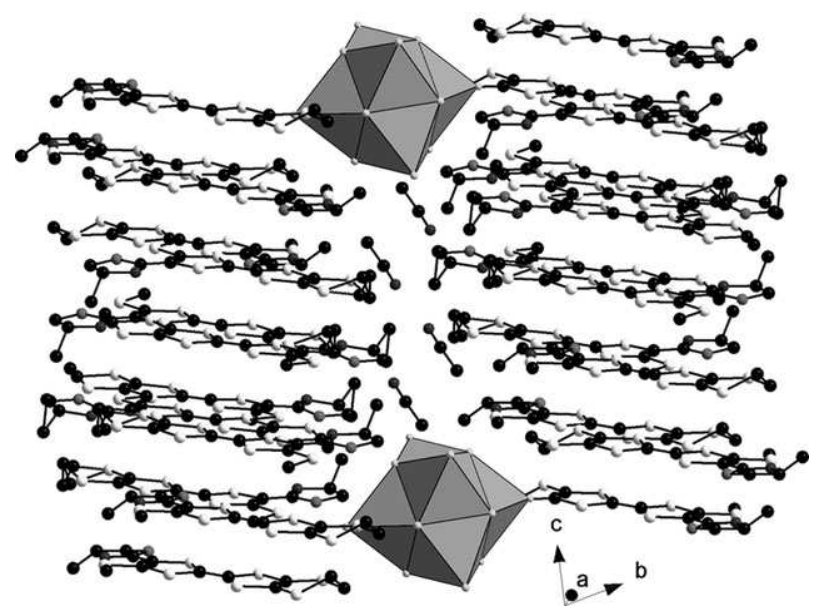

Fig. 12 Packing diagram of $[\mathbf{1}]_{6}\left[\mathrm{Mo}_{6} \mathrm{Cl}_{14}\right]$, with an emphasis on the organic-inorganic segregation. Organic donors organize in slabs in the $a c$ plane. Hydrogen atoms have been omitted for clarity. 


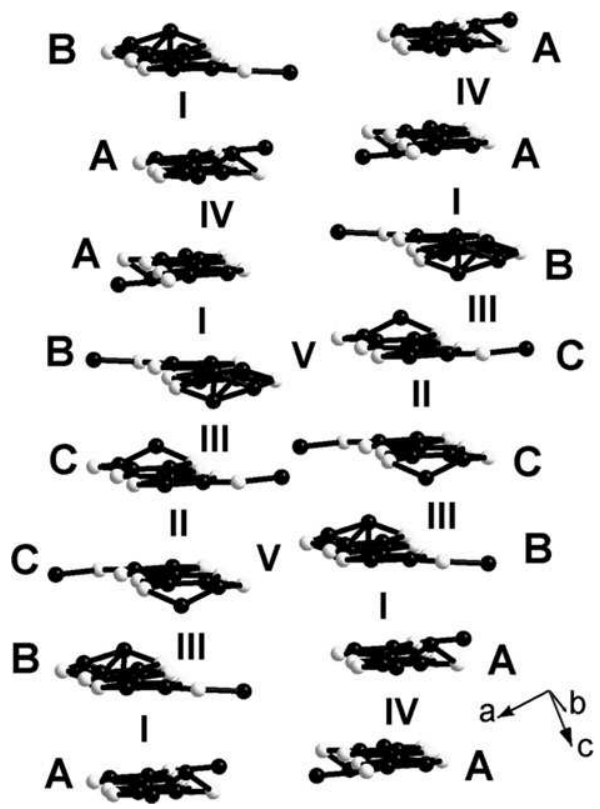

Fig. 13 Parallel stacks of donors in the structure of $[1 \mathbf{a}]_{6}\left[\mathrm{Mo}_{6} \mathrm{Cl}_{14}\right]$, with an emphasis on S...S intermolecular distances shorter than $4 \AA$, identified as interactions $\mathbf{I}-\mathbf{V}$. Oxazoline rings and hydrogen atoms have been omitted for clarity.

system is strongly localized, with two unpaired electrons. The analysis of the calculated interaction energies $\beta_{\text {номо-номо }}$ (Table 3) allows for an easy understanding of the weak dispersion of the bands. First, there is only one weak interstack interaction $(\mathbf{V})$, suggesting that lateral interactions are not expected to be significant. This could be a likely consequence of the presence of the SMe group, hampering the side interactions. Thus the donors layer should be considered as a series of almost non-interacting parallel stacks. Within a stack we identified four different sizeable interactions. Nevertheless, interaction III, between B and C, appears to be extremely weak, thus leading to an obvious lack of delocalization accounting for a band formation mechanism. Therefore, as far as the HOMO-HOMO interactions are concerned, the system can be described in a first approximation as a network of two discrete units, i.e. a dimer $\mathrm{C}-\mathrm{C}$ and a tetramer $\mathrm{B}-\mathrm{A}-\mathrm{A}-\mathrm{B}$, in weak interaction. Furthermore, when analyzing the relative energies of the HOMOs of $\mathbf{A}(-8.606 \mathrm{eV}), \mathbf{B}$ $(-8.763 \mathrm{eV})$ and $\mathbf{C}(-8.580 \mathrm{eV})$, it appears clearly that the energy levels for $\mathbf{A}$ and $\mathbf{C}$ are quite similar, which involves that the calculated $\beta_{\text {номо-номо energies are indeed a very good }}$ estimate of the interaction strengths between $\mathbf{A}-\mathbf{A}$ and $\mathbf{C}-\mathbf{C}$. This is obviously not the case for the interaction between $\mathbf{B}$ and another molecule, since the HOMO level of $\mathbf{B}$ is roughly

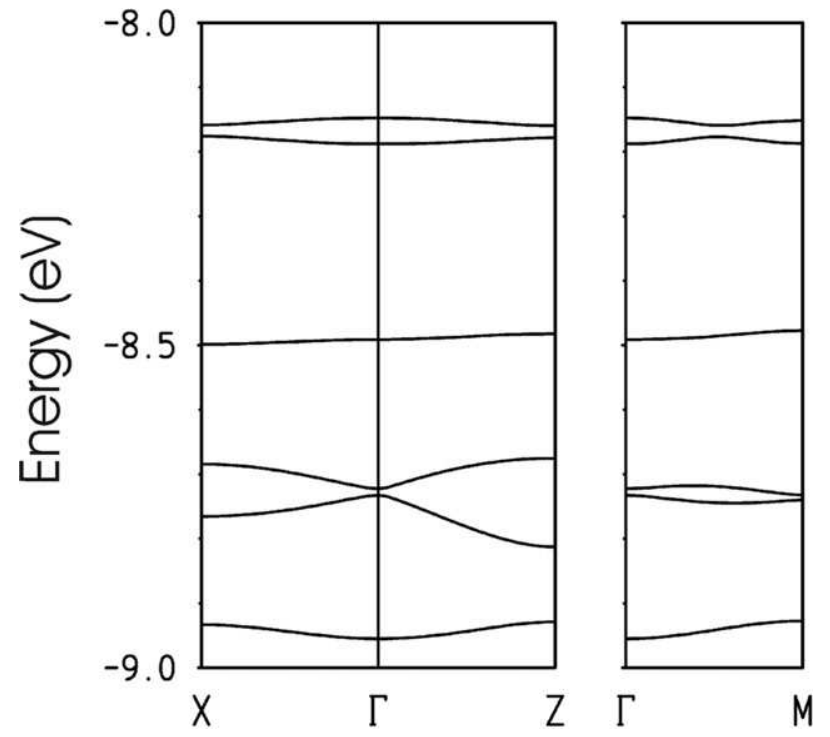

Fig. 14 Calculated band structure for $[1 \mathbf{a}]_{6}\left[\mathrm{Mo}_{6} \mathrm{Cl}_{14}\right]: \Gamma=(0,0)$, $X=\left(a^{*} / 2,0\right), Z=\left(0, c^{*} / 2\right)$ and $M=\left(a^{*} / 2, c^{*} / 2\right)$.

$0.17 \mathrm{eV}$ lower than those of $\mathbf{A}$ and $\mathbf{C}$, and, according to the perturbation theory, stipulating that the interaction between two orbitals is inversely proportional to the energy difference between them, the effective interaction is expected to be much weaker than indicated by the $\beta_{\text {Номо-номо }}$ interaction energy. This affects especially the interaction $\mathbf{I}(\mathbf{A}-\mathbf{B})$, which thus becomes largely inferior to II $(\mathbf{C}-\mathbf{C})$ and IV $(\mathbf{A}-\mathbf{A})$, whereas III and $\mathbf{V}$ were already quite weak. As a consequence, the system can now be considered as a network of mixed-valence dimers $(\mathbf{A})_{2}{ }^{+}$, slightly interacting with neutral molecules $\mathbf{B}$, and mixed valence dimers $(\mathbf{C})_{2}{ }^{+} \cdot$ almost isolated. As already mentioned, the oxidation state of the donors is also in agreement with the $\mathrm{C}=\mathrm{C}$ and $\mathrm{C}-\mathrm{S}$ distances (Table 1).

This description accounts very well for the calculated band structure at different points of the first Brillouin zone. The two most energetic bands are generated at $90 \%$ from the dimer $\mathbf{C}-\mathbf{C}$ for one of them, and from the tetramer $\mathbf{B}-\mathbf{A}-\mathbf{A}-\mathbf{B}$ for the other. In the latter, the contributions can be assigned at $83 \%$ on the dimer $\mathbf{A}-\mathbf{A}$ and only $8 \%$ on each of the donors $\mathbf{B}$ which thus, can be considered as neutral. Now the question arises why donors B prefer to stay neutral in spite of a favorable overlap with $\mathbf{A}$, which is prone to promote a strong interaction leading to a charge delocalization at least inside the tetrameric unit $\mathbf{B}-\mathbf{A}-\mathbf{A}-\mathbf{B}$.

The rationale for this peculiar behaviour is clearly emphasized in Fig. 15, in which the favourable electrostatic interactions between $(\mathbf{A})_{2}{ }^{+}$or $(\mathbf{C})_{2}{ }^{+} \cdot$ and $\mathrm{Mo}_{6} \mathrm{Cl}_{14}{ }^{2-}$ dianions are

Table 3 Intermolecular interactions associated to $\mathrm{S} \cdots \mathrm{S}$ contacts shorter than $4 \AA$ in $[\mathbf{1} \mathbf{a}]_{6}\left[\mathrm{Mo}_{6} \mathrm{Cl}_{14}\right]$, with the corresponding interaction energies $\mid \beta_{\text {НОмо-номо }}$

\begin{tabular}{lll}
\hline Interaction & $\mathrm{S} \cdots \mathrm{S}(\AA)$ & $\mid \beta_{\mathrm{HOMO}-\mathrm{HOMO}}(\mathrm{eV})$ \\
\hline I $(\mathbf{A}-\mathbf{B})$ & $3.72,3.75,3.78,3.79,3.85,3.87,3.88,3.91,3.93,3.96$ & 0.3380 \\
II $(\mathbf{C}-\mathbf{C})$ & $3.63(\times 2), 3.69(\times 2), 3.89(\times 2), 3.98(\times 2)$ & 0.4518 \\
III $(\mathbf{C}-\mathbf{B})$ & $3.83,3.96,3.99$ & 0.0032 \\
IV $(\mathbf{A}-\mathbf{A})$ & $3.66(\times 2), 3.70(\times 2), 3.81(\times 2), 3.90(\times 2), 3.91(\times 2), 3.93(\times 2)$ & 0.4278 \\
V $(\mathbf{B}-\mathbf{C})$ & $3.59,3.71,3.92$ & 0.0818 \\
\hline
\end{tabular}




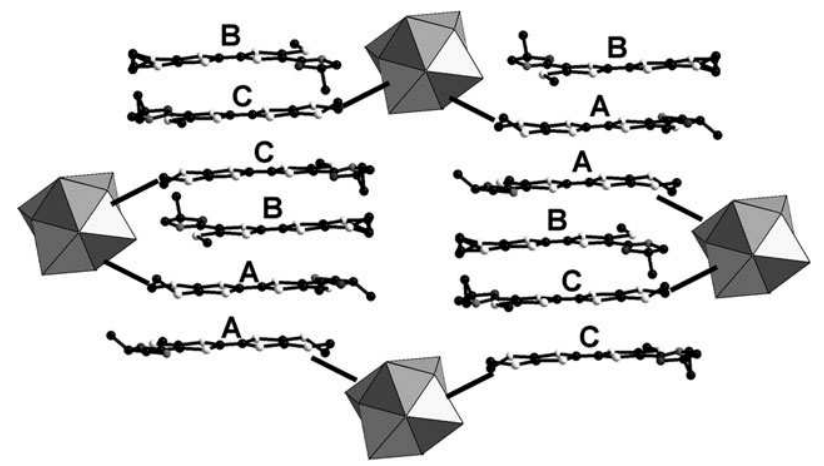

Fig. 15 View of the structure of $\left[\mathbf{1 a}_{6}\left[\mathrm{Mo}_{6} \mathrm{Cl}_{14}\right]\right.$, showing the favorable electrostatic interactions between the charged donors $\mathbf{A}$ and $\mathbf{C}$ and the dianionic clusters.

highlighted. Indeed, the positive charge of a donor is almost completely localized within the EDT-TTF moiety. It follows then that donors $\mathbf{B}$ are completely electrostatically isolated from the dianions, since $\mathbf{B}$ approach the clusters through the oxazoline substituent, and on the opposite side they are close to other $\mathbf{B}$ donors. Therefore, there is no energy gain in the eventuality of delocalizing some positive charge within $\mathbf{B}$, contrary to $\mathbf{A}$ and $\mathbf{C}$ facing the dianions with the EDT-TTF side. As a consequence, each cluster interacts electrostatically with two dimers $(\mathbf{A})_{2}{ }^{+}$and two dimers $(\mathbf{C})_{2}{ }^{+} \bullet$, such as the layer can be seen as a superposition of chains $\mathrm{Mo}_{6} \mathrm{Cl}_{14}{ }^{2-} \cdots(\mathbf{C})_{2}{ }^{+} \cdot \cdots \mathrm{Mo}_{6} \mathrm{Cl}_{14}{ }^{2-} \cdots$ and $\mathrm{Mo}_{6} \mathrm{Cl}_{14}{ }^{2-}$ $\cdots(\mathbf{A})_{2}{ }^{+} \cdot \cdots \mathrm{Mo}_{6} \mathrm{Cl}_{14}{ }^{2-} \cdots$, with voids filled by neutral $\mathbf{B}$ and solvent molecules. It is thus clear that both the shape and the charge of the cluster are likely to have a strong influence on the structure and transport properties of this salt.

However, the charge localization within hardly interacting mixed-valence dimers of donors suggests a semiconducting behavior at most. Single-crystal conductivity and thermoelectric power measurements show indeed an activated regime throughout all the temperature range. $[\mathbf{1 a}]_{6}\left[\mathrm{Mo}_{6} \mathrm{Cl}_{14}\right]$ is thus a semiconductor with a room-temperature conductivity of $2.7 \times$ $10^{-3} \mathrm{~S} \mathrm{~cm}^{-1}$, and an activation energy of $248 \mathrm{meV}$ (Fig. 16).

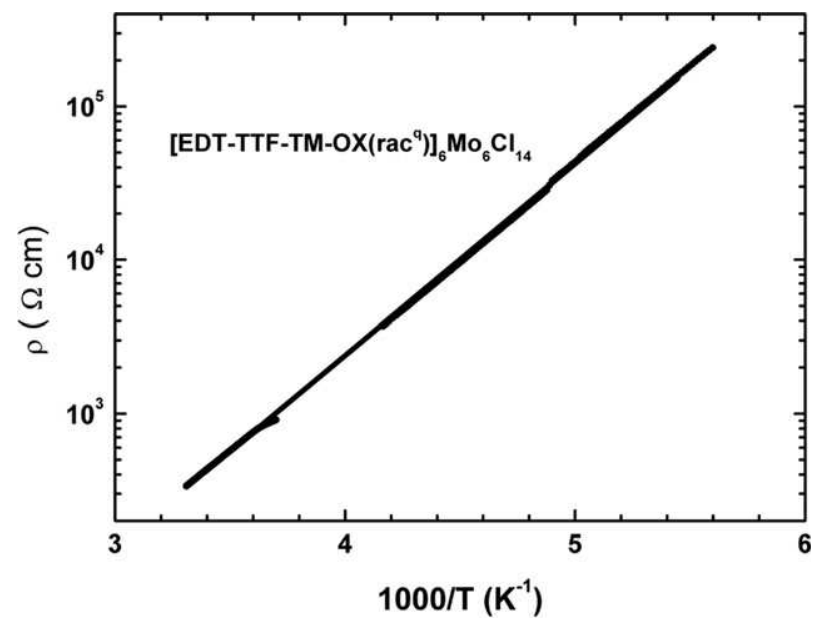

Fig. 16 Single-crystal electrical resistivity for $[\mathbf{1 a}]_{6}\left[\mathrm{Mo}_{6} \mathrm{Cl}_{14}\right]$.

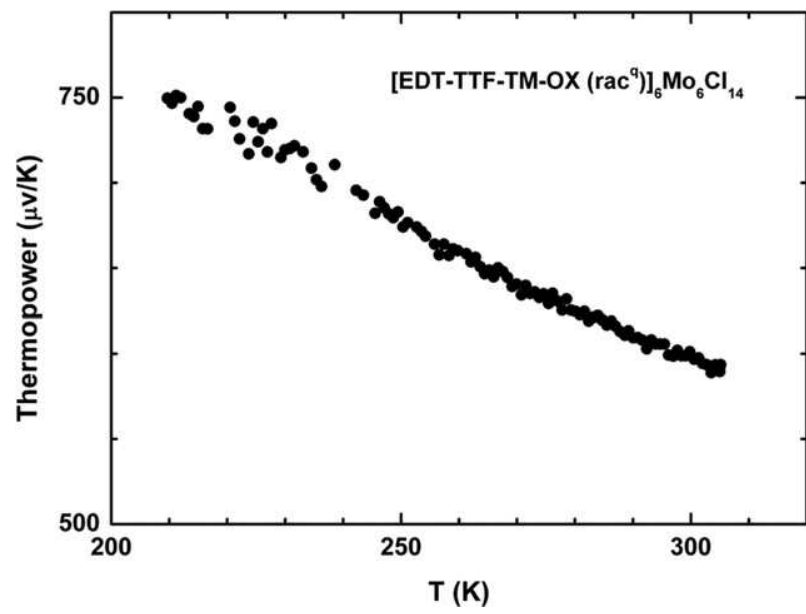

Fig. 17 Thermoelectric power measurement for $\left[\mathbf{1 a}_{6}\left[\mathrm{Mo}_{6} \mathrm{Cl}_{14}\right]\right.$.

Also, the thermoelectric power follows approximately a $1 / T$ law, typical for a semiconducting behavior, ${ }^{28}$ with positive values in the whole range of temperature, indicating that the major charge carriers are holes (Fig. 17).

Moreover, magnetic susceptibility measurements are in agreement with a structure containing radical centers. The compound is paramagnetic following a Curie-Weiss law $(C=$ $0.361 \mathrm{~cm}^{3} \mathrm{~K} \mathrm{~mol}{ }^{-1}$ and $\theta=-1.8 \mathrm{~K}$ ). The Curie constant confirms the presence of only one $S=1 / 2$ spin for three TTF molecules. The Weiss constant indicates very weak antiferromagnetic interactions between radical centers that can be considered as almost isolated in the structure (Fig. 18).

\section{A 4:1 radical cation salt of $1 \mathrm{a}$ with the $\mathrm{Mo}_{6} \mathrm{Cl}_{14}{ }^{2-}$ dianion}

The versatility and adaptability of this $\mathbf{1 a}-\mathrm{Mo}_{6} \mathrm{Cl}_{14}{ }^{2-}$ system prompted us to perform a third electrocrystallization experiment, now in a mixture of $\mathrm{MeCN}-\mathrm{CH}_{2} \mathrm{Cl}_{2}$. To our surprise, a different salt was thus obtained, formulated as $[\mathbf{1} \mathbf{a}]_{4}\left[\mathrm{Mo}_{6} \mathrm{Cl}_{14}\right]$, with an intermediary stoichiometry of $4: 1$ with respect to the

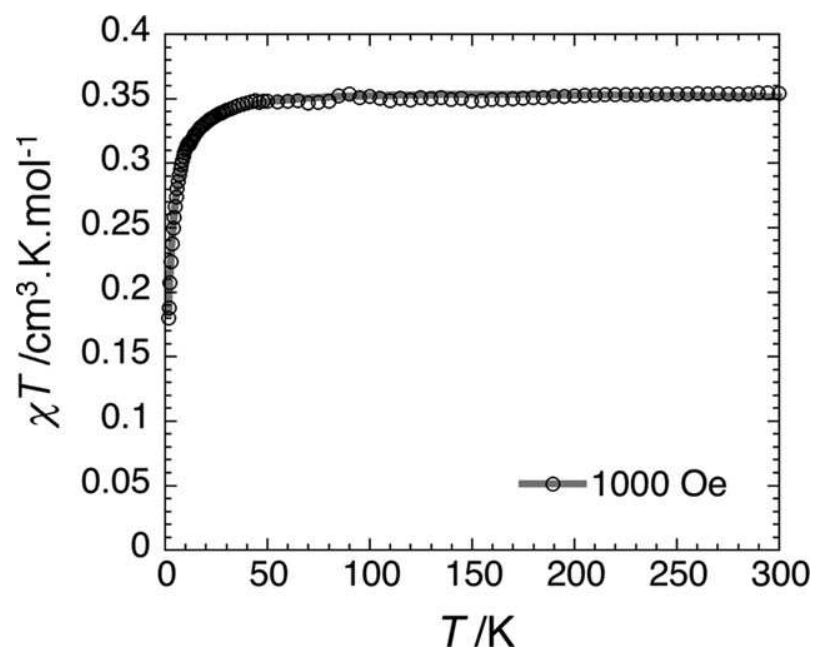

Fig. $18 \chi T$ vs. $T$ plot for $1 / 2[\mathbf{1}]_{6}\left[\mathrm{Mo}_{6} \mathrm{Cl}_{14}\right]$ (polycrystalline sample) under $1 \mathrm{kOe}$. The gray line represents the best fit obtained with the Curie-Weiss law described in the text. 


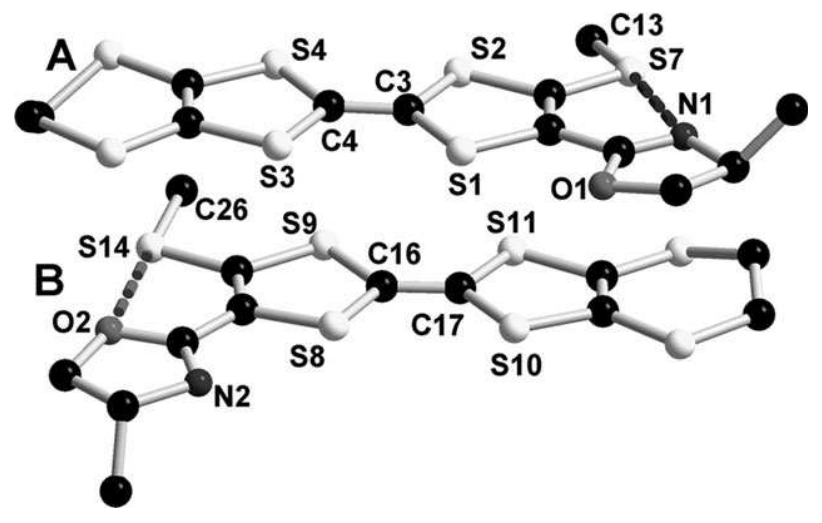

Fig. 19 View of the two independent TTF molecules in the structure of $[\mathbf{1 a}]_{4}\left[\mathrm{Mo}_{6} \mathrm{Cl}_{14}\right]$. Selected parameters: A: $\mathrm{N}(1) \cdots \mathrm{S}(7) 2.92 \AA$, $\mathrm{N}(1) \cdots \mathrm{S}(7)-\mathrm{Me} 174.1^{\circ}$; B: $\mathrm{O}(2) \cdots \mathrm{S}(14) 2.96 \AA ̊ 丿, \mathrm{O}(2) \cdots \mathrm{S}(14)-\mathrm{Me}$ $174.1^{\circ}$. Hydrogen atoms have been omitted for clarity.

first two salts previously described. The new compound crystallizes in the triclinic system, group space $P \overline{1}$, with two independent donors in general positions and one cluster located on an inversion center in the unit cell (Fig. 19).

As in the previous case, both s-cis (molecule $\mathbf{A}$ ) and s-trans (molecule B) conformations are observed, characterized by $\mathrm{N} \cdots \mathrm{S}$ and $\mathrm{O} \cdots \mathrm{S}$ nonbonded interactions, respectively. Once again, this result confirms the trend drawn from theoretical calculations on $\mathbf{1}^{\prime+}$ (vide supra). The analysis of $\mathrm{C}=\mathrm{C}$ and $\mathrm{C}-\mathrm{S}$ intramolecular bonds (Table 1) suggests that both types of donors are in mixed valence state, which allows to define the salt as $\left[(\mathbf{A})_{2}{ }^{+}(\mathbf{B})_{2}{ }^{+}\right]\left[\mathrm{Mo}_{6} \mathrm{Cl}_{14}\right]^{2-}$. The packing diagram shows a clear organic-inorganic segregation along $c$, with donors stacking approximately along $b$ (Fig. 20).

The careful analysis of the packing mode of donors within an organic layer (Fig. 21), along with that of intermolecular S...S distances and the corresponding HOMO-HOMO inter-

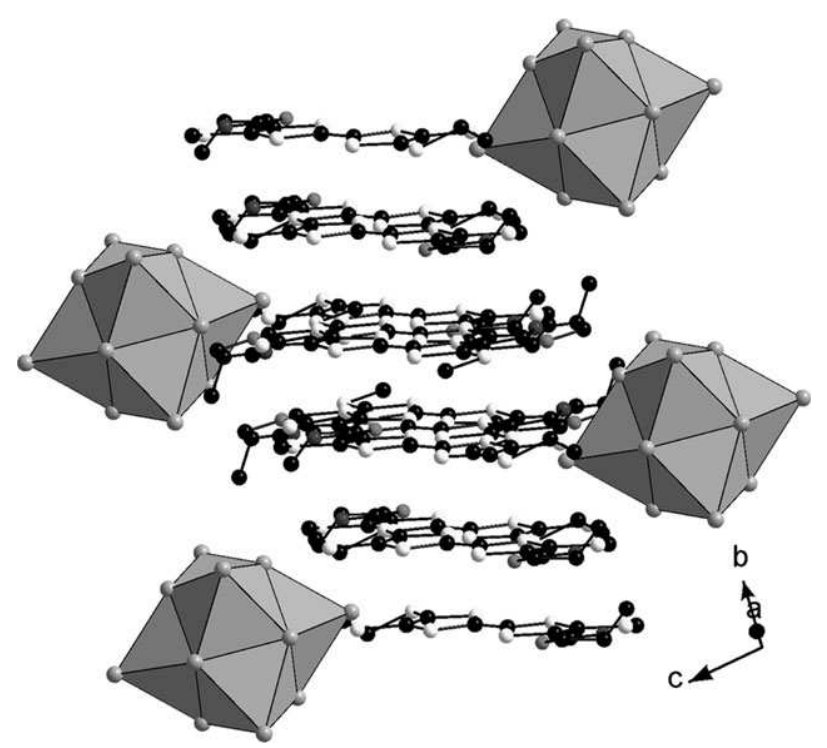

Fig. 20 Packing diagram of $[\mathbf{1 a}]_{4}\left[\mathrm{Mo}_{6} \mathrm{Cl}_{14}\right]$, with an emphasis on the organic-inorganic segregation. Organic donors organize in slabs in the $a b$ plane. Hydrogen atoms have been omitted for clarity.

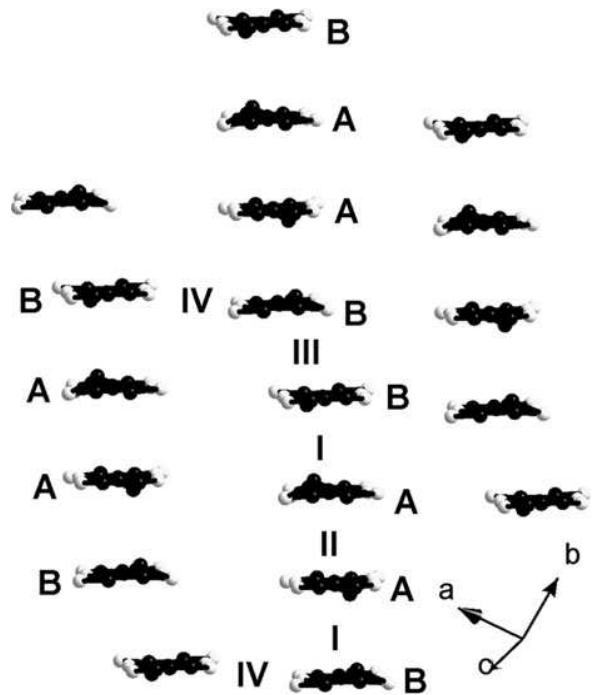

Fig. 21 Parallel stacks of donors in the structure of $[\mathbf{1 a}]_{4}\left[\mathrm{Mo}_{6} \mathrm{Cl}_{14}\right]$, with an emphasis on S..S intermolecular distances shorter than $4 \AA$, identified as interactions I-IV. Oxazoline rings, SMe groups and hydrogen atoms have been omitted for clarity.

action energies $\beta_{\text {номо-номо (Table } 4 \text { ), evidence several }}$ features.

First, as far as one refers to the HOMO-HOMO interactions it is clear that the donors organize in tetrameric units $[\mathbf{B}-\mathbf{A}-\mathbf{A}-\mathbf{B}]$ interacting each other very poorly, probably because of the lateral offset of donors $\mathbf{B}$. Indeed, large intra-

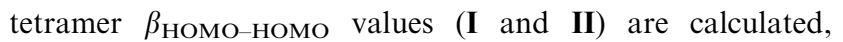
whereas interactions III (B-B) intra-stack and IV (B-B) inter-stack are much weaker. Therefore, one can expect massive charge localization within a dicationic tetrameric unit, and, subsequently, weak extended delocalization through band formation. Accordingly, tight-binding calculations yielded a band structure diagram showing a flat upper band, well separated from the next one, expected to be completely empty if considering the +0.5 mean charge per donor (Fig. 22). The energy location of the different bands closely follows that of the discrete energy levels of a $[\mathbf{B}-\mathbf{A}-\mathbf{A}-\mathbf{B}]^{2+}$ unit, as expected from the analysis.

The weak dispersion of the bands is the direct consequence of the lack of interaction between the tetrameric units, which is likely to leading to a rather poor conductivity of this salt. This analysis was indeed confirmed by thermoelectric power measurements on $[\mathbf{1 a}]_{4}\left[\mathrm{Mo}_{6} \mathrm{Cl}_{14}\right]$ (Fig. 23).

Thermoelectric power becomes more negative upon cooling following a semiconducting behavior, with large, but negative

Table 4 Intermolecular interactions associated to $\mathrm{S} \cdots \mathrm{S}$ contacts shorter than $4 \AA$ in $[\mathbf{1 a}]_{4}\left[\mathrm{Mo}_{6} \mathrm{Cl}_{14}\right]$, with the corresponding interaction energies $\left|\beta_{\text {НОMO-HOMO }}\right|$

\begin{tabular}{lll}
\hline Interaction & $\mathrm{S} \cdots \mathrm{S}(\AA)$ & $\begin{array}{l}\left|\beta_{\text {HОмо-номо }}\right| \\
(\mathrm{eV})\end{array}$ \\
\hline I $(\mathbf{A}-\mathbf{B})$ & $3.65,3.66,3.68,3.69,3.73,3.76$ & 0.5308 \\
II $(\mathbf{A}-\mathbf{A})$ & $3.69(\times 2), 3.74(\times 2), 3.84(\times 2)$, & 0.4175 \\
& $3.86(\times 2)$ & 0.0580 \\
III $(\mathbf{B}-\mathbf{B})$ & $3.84(\times 2), 3.95(\times 2)$ & 0.0776 \\
IV $(\mathbf{B}-\mathbf{B})$ & $3.59(\times 2), 3.87$ & \\
\hline
\end{tabular}




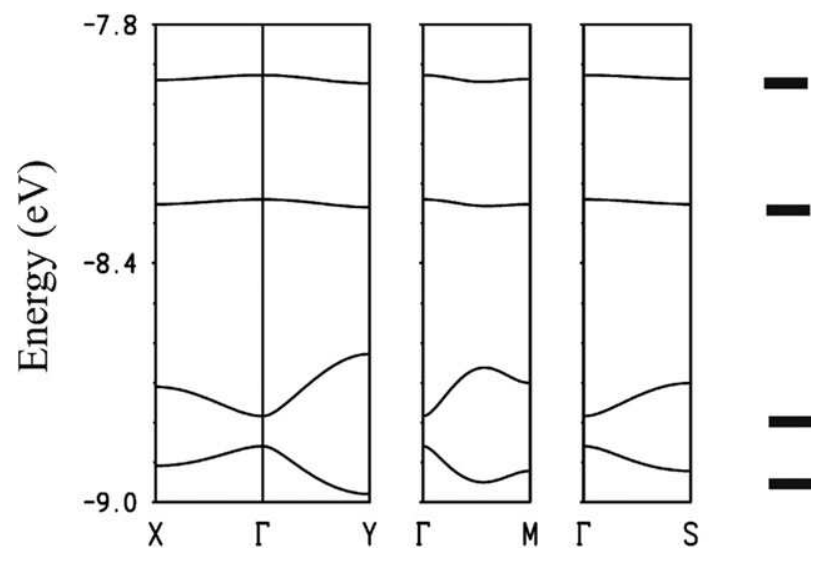

Fig. 22 Calculated band structure for $[\mathbf{1} \mathbf{a}]_{4}\left[\mathrm{Mo}_{6} \mathrm{Cl}_{14}\right] ; \Gamma=(0,0), X$ $=\left(a^{*} / 2,0\right), Y=\left(0, b^{*} / 2\right), M=\left(a^{*} / 2, b^{*} / 2\right)$ and $S=\left(-a^{*} / 2, c^{*} / 2\right)$. Discrete levels at the right are those for an isolated tetramer unit.

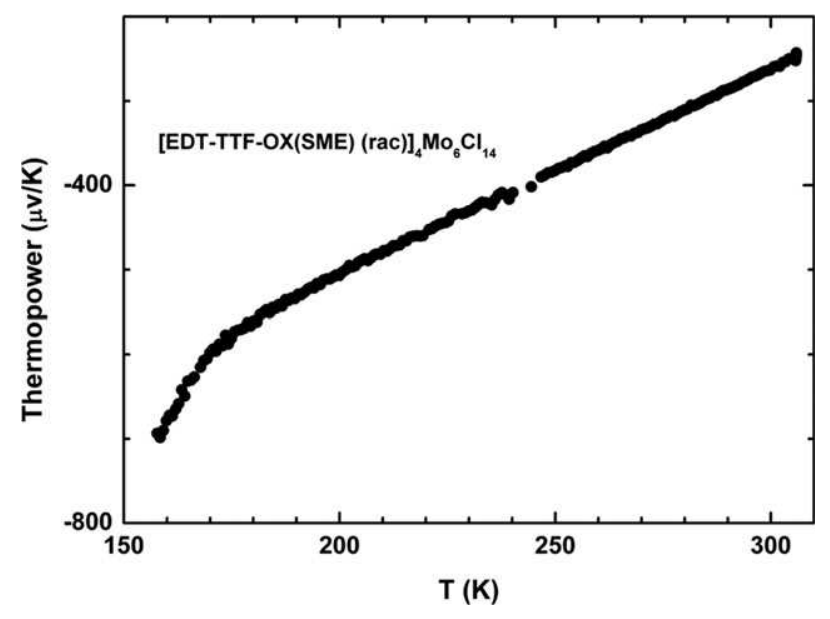

Fig. 23 Thermoelectric power measurement for $[\mathbf{1 a}]_{4}\left[\mathrm{Mo}_{6} \mathrm{Cl}_{14}\right]$.

values in the whole temperature range. Thus, contrary to the 6:1 salt, this time the dominant charge carriers are electrons.

The synthesis of the three different salts with the same donor and anion by a fine tuning of the electrocrystallization solvent is certainly largely due to the flexibility of the donor $\mathbf{1}$, able to adapt two isoenergetic conformations, with a low energy barrier in between, thanks to unprecedented $\mathrm{N} \cdots \mathrm{S}$ and $\mathrm{O} \cdots \mathrm{S}$ nonbonded interactions in the TTF series.

\section{Conclusion}

Racemic and enantiopure EDT-TTF-(SMe)-oxazoline donors have been synthesized with the purpose to promote intramolecular $\mathrm{S} \cdots \mathrm{N}$ or $\mathrm{S}$...O weakly-bonding interactions prone to stabilize planar conformations, and to investigate their relative stability in neutral or radical cation states. Solid-state structure analysis of the neutral donors shows the establishment of only S . . O interactions, characterized by short S. . O distances and linear MeS...O motifs. Theoretical calculations at DFT/ B3LYP level, combined with an "atoms in molecules" (AIM) analysis on the model system $\mathbf{1}^{\prime}$ allowed to evidence and characterize undoubtedly both types of interactions, which were found to be equally strong. Moreover, the calculated energy barrier between the two forms was as low as $7.1 \mathrm{kcal}$ $\mathrm{mol}^{-1}$ in the case of the simpler model $\mathbf{1}^{\prime \prime}$. The relative stability of the s-cis $(\mathrm{N} \cdots \mathrm{S})$ and $s$-trans $(\mathrm{O} \cdots \mathrm{S})$ conformations was further evaluated in the radical cation salt $\mathbf{1}^{\prime+} \bullet$, allowing to estimate that oxidation of TTF tends to favor the occurrence of $s$-cis conformation when compared to the neutral case. This feature was nicely evidenced by the synthesis of three different radical cation salts with the racemic donor 1 a and the dianionic cluster $\mathrm{Mo}_{6} \mathrm{Cl}_{14}{ }^{2-}$, the stoichiometries of which varied upon changing the electrocrystallization solvent. Two of the salts, i.e. $[\mathbf{1 a}]_{6}\left[\mathrm{Mo}_{6} \mathrm{Cl}_{14}\right]$ and $[\mathbf{1}]_{4}\left[\mathrm{Mo}_{6} \mathrm{Cl}_{14}\right]$, were found to have semiconducting behavior, as determined by appropriate physical measurements, combined with tight-binding calculations. In these two cases the occurrence of both N $\cdots \mathrm{S}$ and $\mathrm{O} \cdots \mathrm{S}$ nonbonded interactions was observed, demonstrating that the mutual influence between these novel intramolecular interactions in the TTF series and oxidation state can provide unprecedented structures and interesting molecular materials.

\section{Experimental}

\section{General comments}

Dry $\mathrm{CH}_{2} \mathrm{Cl}_{2}$ and $\mathrm{CH}_{3} \mathrm{CN}$ were obtained by distillation over $\mathrm{P}_{2} \mathrm{O}_{5}$ and THF was distilled over sodium and benzophenone. Nuclear magnetic resonance spectra were recorded on a Bruker Avance DRX 500 spectrometer operating at 500.04 $\mathrm{MHz}$ for ${ }^{1} \mathrm{H}, 125.75 \mathrm{MHz}$ for ${ }^{13} \mathrm{C}$. Chemical shifts are expressed in parts per million ( $\mathrm{ppm}$ ) downfield from external TMS. The following abbreviations are used: s, singlet; $d$, doublet; t, triplet; m, multiplet; b, broad. MALDI-TOF MS spectra were recorded on Bruker Biflex-IIITM apparatus, equipped with a $337 \mathrm{~nm} \mathrm{~N}_{2}$ laser. Elemental analyses were performed by the "Service d'Analyse du CNRS" at Gif/ Yvette, France. Compound $\mathbf{2}$ was prepared according to a published procedure. ${ }^{18}$

\section{Syntheses}

4-(Methylthio)-5-carbomethoxy-1,3-dithiol-2-one (3). A suspension of $\mathrm{Hg}(\mathrm{OAc})_{2}(76 \mathrm{~g}, 238 \mathrm{mmol})$ in glacial acetic acid $(610 \mathrm{~mL})$ was added to a solution of 4-(methylthio)-5-carbomethoxy-1,3-dithiol-2-thione ${ }^{19}(22.27 \mathrm{~g}, 93.4 \mathrm{mmol})$ in chloroform $(340 \mathrm{~mL})$. The reaction mixture was refluxed for $2 \mathrm{~h}$. After filtration through Celite, the filtrate was washed three times with water, two times with saturated $\mathrm{NaHCO}_{3}$, and again with water. After drying over $\mathrm{MgSO}_{4}$, filtration, evaporation, and drying in vacuo, the resulting yellow-brown powder was recrystallized in isopropanol (17.47 $\mathrm{g}, 84 \%)$. Mp $133{ }^{\circ} \mathrm{C} .{ }^{1} \mathrm{H}$ NMR $\left(\mathrm{CDCl}_{3}, \delta, \mathrm{ppm}\right): 2.60\left(\mathrm{~s}, 3 \mathrm{H}, \mathrm{SCH}_{3}\right), 3.87$ (s, $\left.3 \mathrm{H}, \mathrm{CO}_{2} \mathrm{CH}_{3}\right) .{ }^{13} \mathrm{C} \mathrm{NMR}\left(\mathrm{CDCl}_{3}, \delta, \mathrm{ppm}\right): 18.5\left(\mathrm{SCH}_{3}\right), 52.7$ $\left(\mathrm{OCH}_{3}\right), 110.8\left(\mathrm{CSCH}_{3}\right), 146.7\left(\mathrm{CCO}_{2} \mathrm{Me}\right), 160.3(\mathrm{MeOC}(\mathrm{O}))$, $187.5(C=\mathrm{O})$. Anal. Calc. for $\mathrm{C}_{6} \mathrm{H}_{6} \mathrm{O}_{3} \mathrm{~S}_{3}: \mathrm{C}, 32.4 ; \mathrm{H}, 2.7 \%$. Found: C, 32.3; H, 2.7\%.

EDT-TTF-(SMe)-CO $\mathbf{C O}_{2} \mathrm{Me}$ (4). The precursors 2 (4.48 g, $20 \mathrm{mmol}$ ) and 3 (4.45 g, $20 \mathrm{mmol})$ were dissolved in freshly distilled trimethyl phosphite $(70 \mathrm{~mL})$, and then heated at $110{ }^{\circ} \mathrm{C}$ for $4 \mathrm{~h}$. Upon standing overnight at room temperature, 
the side product BEDT-TTF precipitated. After filtration and concentration of the filtrate under reduced pressure, the crude product was purified by silica gel chromatography with toluene as eluent, affording 4, after evaporation of the solvent, as a red solid $(2.36 \mathrm{~g}, 30 \%)$. Mp $155{ }^{\circ} \mathrm{C} .{ }^{1} \mathrm{H} \mathrm{NMR}\left(\mathrm{CDCl}_{3}, \delta\right.$, ppm): 2.59 (s, 3H, $\mathrm{SCH}_{3}$ ), 3.29 (s, 4H, $\left.\mathrm{SCH}_{2} \mathrm{CH}_{2} \mathrm{~S}\right), 3.79$ (s, $\left.3 \mathrm{H}, \mathrm{CO}_{2} \mathrm{CH}_{3}\right) \cdot{ }^{13} \mathrm{C} \mathrm{NMR}\left(\mathrm{CDCl}_{3}, \delta, \mathrm{ppm}\right): 18.2\left(\mathrm{SCH}_{3}\right), 30.2$ $\left(\mathrm{SCH}_{2} \mathrm{CH}_{2} \mathrm{~S}\right), 52.4\left(\mathrm{OCH}_{3}\right), 109.3-112.1-112.8-113.5-114.4$ (2 $C=C \quad$ and $\quad \mathrm{C}=C-\mathrm{SMe}), \quad 148.3 \quad\left(\mathrm{C}=C-\mathrm{CO}_{2} \mathrm{Me}\right), \quad 160.5$ $\left(\mathrm{CO}_{2} \mathrm{Me}\right)$. MS (MALDI-TOF): $m / z=397.76 \mathrm{M}^{+}$. IR $(\mathrm{KBr}$, $\mathrm{cm}^{-1}$ ): 1697 (s). Anal. Calc. for $\mathrm{C}_{11} \mathrm{H}_{10} \mathrm{O}_{2} \mathrm{~S}_{7}$ : C, 33.1; H, 2.5\%. Found: C, 33.4; H, 2.6\%.

EDT-TTF-(SMe)-COOH (4'). The ester 4 (4.38 g, 10.99 $\mathrm{mmol})$ in dioxane $(260 \mathrm{ml})$ was reacted with $\mathrm{LiOH}$ (2.31 g, 55 $\mathrm{mmol}$, in $40 \mathrm{~mL}$ of degassed water) at room temperature overnight. $\mathrm{HCl}$ solution $(11 \mathrm{~mL}, 5 \mathrm{M})$ was than added and a red solid precipitated. After $15 \mathrm{~min}$ of stirring, $\mathrm{Et}_{2} \mathrm{O}(300 \mathrm{~mL})$ was added and the mixture was further acidified to $\mathrm{pH}=1$ with $5 \mathrm{M} \mathrm{HCl}$. The organic layer was separated, filtrated to afford a red powder, and then the filtrate was dried over $\mathrm{MgSO}_{4}$ and evaporated to give a second crop of red powder. The combined red solids were purified in a Soxhlet with acetone, thus providing quantitatively the acid $\mathbf{4}^{\prime}$. Mp $202{ }^{\circ} \mathrm{C} .{ }^{1} \mathrm{H}$ NMR $\left(\mathrm{CDCl}_{3}, \delta, \mathrm{ppm}\right): 2.57$ (s, 3H, $\left.\mathrm{SCH}_{3}\right), 3.39$ (s, 4H, $\left.\mathrm{SCH}_{2} \mathrm{CH}_{2} \mathrm{~S}\right)$. IR ( $\mathrm{KBr}, \mathrm{cm}^{-1}$ ): 1729 (s), 2500-3000 (b).

EDT-TTF-(SMe)-COCl (5). Acid 4' (1.54 g, 4 mmol) was dissolved in THF $(160 \mathrm{~mL})$ and the solution thus obtained was warmed up to $45{ }^{\circ} \mathrm{C}$ before addition of oxalyl chloride (1.5 $\mathrm{mL}, 16 \mathrm{mmol})$ and pyridine $(4 \mu \mathrm{L})$. After stirring at $45{ }^{\circ} \mathrm{C}$ for $3.5 \mathrm{~h}$, the reaction mixture was concentrated under reduced pressure (to $30 \mathrm{~mL}$ ). The acyl chloride $\mathbf{5}$ precipitated upon addition of hexane $(70 \mathrm{~mL})$, and then it was isolated by filtration and dried under vacuum (1.38 g, 86\%). Mp $209{ }^{\circ} \mathrm{C} .{ }^{1} \mathrm{H}$ NMR $\left(\mathrm{CDCl}_{3}, \delta, \mathrm{ppm}\right): 2.61$ (s, 3H, $\left.\mathrm{SCH}_{3}\right), 3.31$ (s, $4 \mathrm{H}, \mathrm{SCH}_{2} \mathrm{CH}_{2} \mathrm{~S}$ ). IR ( $\mathrm{KBr}, \mathrm{cm}^{-1}$ ): 1712 (s).

$\boldsymbol{\beta}$-hydroxy amides (6a-c). $( \pm)$-, $(R)$ - or $(S)$-2-amino-1-propanol (alaninol) $(160 \mathrm{mg}, 2.14 \mathrm{mmol})$ and distilled triethylamine $(0.48 \mathrm{~mL}, 3.42 \mathrm{mmol})$ were placed in $10 \mathrm{~mL}$ THF. The colorless solution was stirred for 10 min under $\mathrm{N}_{2}$ at room temperature, and then a freshly prepared solution of EDTTTF-(SMe)-COCl 5 (690 mg, $1.71 \mathrm{mmol}$ in $70 \mathrm{~mL}$ THF) was added dropwise. The reaction mixture became orange and a precipitate was formed. After stirring overnight at room temperature, the brown-red mixture was filtrated through Celite, the solvent evaporated, and the crude product purified on silica gel (eluent: THF). The oil obtained after evaporation of solvent was diluted in a small volume of THF (5 to $8 \mathrm{~mL}$ ) and dropped onto $400-500 \mathrm{~mL}$ petroleum ether to afford $\mathbf{6 a}-\mathbf{c}$ as red-orange powders $(670 \mathrm{mg}, 90 \%) .{ }^{1} \mathrm{H} \mathrm{NMR}\left(\mathrm{CDCl}_{3}, \delta\right.$, ppm): $1.24\left(\mathrm{~d},{ }^{3} \mathrm{~J}=6.8 \mathrm{~Hz}, 3 \mathrm{H}, \mathrm{CH}_{3}\right), 2.54\left(\mathrm{~s}, 3 \mathrm{H}, \mathrm{SCH}_{3}\right), 3.29$ (s, $\left.4 \mathrm{H}, \mathrm{S}-\mathrm{CH}_{2}-\mathrm{CH}_{2}-\mathrm{S}\right), 3.60\left(\mathrm{dd},{ }^{2} J=11.0\right.$ and ${ }^{3} J=5.5 \mathrm{~Hz}$, $\left.1 \mathrm{H}, \mathrm{CH}_{2} \mathrm{O}\right), 3.72\left(\mathrm{dd},{ }^{2} J=11.0\right.$ and $\left.^{3} J=3.7 \mathrm{~Hz}, 1 \mathrm{H}, \mathrm{CH}_{2} \mathrm{O}\right)$, $4.14\left(\mathrm{~m}, 1 \mathrm{H}, \mathrm{NH}-\mathrm{CH}-\left(\mathrm{CH}_{3}\right)-\mathrm{CH}_{2} \mathrm{O}\right), 7.21\left(\mathrm{~d},{ }^{3} \mathrm{~J}=8.4 \mathrm{~Hz}\right.$, $1 \mathrm{H}, \mathrm{NH}) .{ }^{13} \mathrm{C} \mathrm{NMR}\left(\mathrm{CDCl}_{3}, \delta, \mathrm{ppm}\right): 17.0\left(\mathrm{SCH}_{3}\right), 19.8$ $\left(\mathrm{CH}_{3}\right), 30.2\left(\mathrm{~S}-\mathrm{CH}_{2}-\mathrm{CH}_{2}-\mathrm{S}\right), 48.3(\mathrm{CH}-\mathrm{NH}), 66.6\left(\mathrm{CH}_{2} \mathrm{OH}\right)$, 113.5 and $114.4 \quad(2 \quad \mathrm{C}=\mathrm{C}), \quad 128.7 \quad(=\mathrm{C}-\mathrm{SMe}), 133.7$ $(=C-\mathrm{C}=\mathrm{O}), \quad 159.8 \quad(\mathrm{NH}-C=\mathrm{O}) . \quad$ MS $\quad($ MALDI-TOF): $m / z=440.92 \mathrm{M}^{+}$. Anal. Calc. for $\mathrm{C}_{13} \mathrm{H}_{15} \mathrm{NO}_{2} \mathrm{~S}_{7}: \mathrm{C}, 35.3$; H, 3.4; N, 3.2\%. Found: C, 35.2; H, 3.4; N, 3.1\%.

EDT-TTF-SMe-OX (1a-c). A solution of hydroxyamide 6a-c (540 mg, $1.22 \mathrm{mmol})$ and distilled $\mathrm{NEt}_{3}(0.34 \mathrm{~mL}, 2.44$ $\mathrm{mmol})$ in $30 \mathrm{~mL} \mathrm{THF}$ was cooled at $0{ }^{\circ} \mathrm{C}$, and then, mesyl chloride $(0.19 \mathrm{~mL}, 2.43 \mathrm{mmol})$ was added at once. After 30 min of stirring at $0{ }^{\circ} \mathrm{C}$, more $\mathrm{NEt}_{3}(1.53 \mathrm{~mL}, 10.98 \mathrm{mmol})$ was added and the reaction mixture was subsequently heated at $50{ }^{\circ} \mathrm{C}$ until the intermediate mesylate disappeared (monitored by TLC: AcOEt-cyclohexane, 1 : 1), after ca. 20 h. After filtration through Celite, the solvent was evaporated and the crude product was purified by silica gel chromatography (eluent: AcOEt-cyclohexane, $1: 1$ ), to afford 1a-c as dark red powders $(450 \mathrm{mg}, 87 \%)$ after evaporation of solvents. Suitable single crystals for X-ray analysis were grown upon partial slow evaporation of a solution of $\mathbf{1 a}$ in $\mathrm{CH}_{2} \mathrm{Cl}_{2}$-cyclohexane, $1: 1$, or recrystallization from a $\mathrm{CH}_{2} \mathrm{Cl}_{2}-$ cyclohexane, 2: 1 mixture (1b,c). Mp $135{ }^{\circ} \mathrm{C}(\mathbf{1 a}), 155{ }^{\circ} \mathrm{C}(\mathbf{1 b}, \mathbf{c}) .{ }^{1} \mathrm{H}$ NMR $\left(\mathrm{CDCl}_{3}, \delta, \mathrm{ppm}\right): 1.31\left(\mathrm{~d},{ }^{3} \mathrm{~J}=6.6 \mathrm{~Hz}, 3 \mathrm{H}, \mathrm{CH}_{3}\right), 2.56$ (s, $\left.3 \mathrm{H}, \mathrm{SCH}_{3}\right), 3.29$ (s, 4H, S-CH $\left.\mathrm{CH}_{2}-\mathrm{CH}_{2}-\mathrm{S}\right), 3.90\left(\mathrm{t},{ }^{3} J={ }^{2} J=\right.$ $7.9 \mathrm{~Hz}, \quad 1 \mathrm{H}, \quad H_{\text {syn }} / \mathrm{CH}_{3}$ of $\left.\mathrm{CH}_{2} \mathrm{O}\right), 4.32 \quad(\mathrm{~m}, 1 \mathrm{H}$, $\left.\mathrm{N}-\mathrm{CH}-\left(\mathrm{CH}_{3}\right)-\mathrm{CH}_{2} \mathrm{O}\right), 4.45\left(\mathrm{dd},{ }^{3} \mathrm{~J}=9.1 \mathrm{~Hz}\right.$ and ${ }^{2} \mathrm{~J}=$ $7.9 \mathrm{~Hz}, 1 \mathrm{H}, \mathrm{H}_{\mathrm{anti}} / \mathrm{CH}_{3}$ of $\left.\mathrm{CH}_{2} \mathrm{O}\right) .{ }^{13} \mathrm{C} \mathrm{NMR}\left(\mathrm{CDCl}_{3}, \delta\right.$, ppm): $18.6(\mathrm{SMe}), 21.3\left(\mathrm{CH}_{3}\right), 30.2$ and $30.3\left(\mathrm{~S}-\mathrm{CH}_{2}-\mathrm{CH}_{2}-\mathrm{S}\right)$, 62.1 (CH-N), $74.8\left(\mathrm{CH}_{2} \mathrm{O}\right), 108.8-112.6-113.0-113.5-114.4(2$ $\mathrm{C}=\mathrm{C}$ and $=C-\mathrm{SMe}), 137.9(=C-\mathrm{C}=\mathrm{N}), 157.3(\mathrm{C}=\mathrm{N})$. MS (MALDI-TOF): $m / z=422.90 \mathrm{M}^{+}$. Anal. Calc. for $\mathrm{C}_{13} \mathrm{H}_{13} \mathrm{NOS}_{7}$ : C, 36.8; H, 3.1; N, 3.3\%. Found: C, 36.9; H, $3.1 ; \mathrm{N}, 3.2 \%$.

X-Ray crystal structure determinations. Details about data collection and solution refinement are given in Table 5. X-Ray diffraction measurements were performed on a Bruker Kappa $\mathrm{CCD}$ diffractometer for 1a, $[\mathbf{1} \mathbf{a}]_{2} \mathrm{Mo}_{6} \mathrm{Cl}_{14},[\mathbf{1} \mathbf{a}]_{4} \mathrm{Mo}_{6} \mathrm{Cl}_{14}$ and on a Stoe Imaging Plate System for $\mathbf{1 b}, \mathbf{1 c},[\mathbf{1} \mathbf{a}]_{6} \mathrm{Mo}_{6} \mathrm{Cl}_{14}$, both operating with a Mo-K $\alpha(\lambda=0.71073 \AA) \mathrm{X}$-ray tube with a graphite monochromator. The structures were solved (SHELXS-97) by direct methods and refined (SHELXL-97) by full-matrix least-square procedures on $F^{2} \cdot{ }^{29}$ All non-H atoms were refined anisotropically, and hydrogen atoms were introduced at calculated positions (riding model), included in structure factor calculations but not refined.

CCDC reference numbers 632610 (1a), 632611 (1b), 632612 (1c), $632613\left([\mathbf{1 a}]_{2} \mathrm{Mo}_{6} \mathrm{Cl}_{14}\right), \quad 632614 \quad\left([\mathbf{1} \mathbf{a}]_{4} \mathrm{Mo}_{6} \mathrm{Cl}_{14}\right)$ and $632615\left([\mathbf{1 a}]_{6} \mathrm{Mo}_{6} \mathrm{Cl}_{14}\right)$. For crystallographic data in CIF or other electronic format see DOI: 10.1039/b701617d

Electrocrystallization. A two-compartment cell was used together with platinum electrodes $(2 \mathrm{~cm}$ long, $1 \mathrm{~mm}$ in diameter) and a current of $1 \mu \mathrm{A}$ at room temperature $(20 \pm$ $\left.2{ }^{\circ} \mathrm{C}\right) .\left[(n-\mathrm{Bu})_{4} \mathrm{~N}\right]_{2} \mathrm{Mo}_{6} \mathrm{Cl}_{14} 0.015 \mathrm{M}$ either in $\mathrm{CH}_{2} \mathrm{Cl}_{2}(14 \mathrm{~mL})$ for $[1 \mathbf{a}]_{2} \mathrm{Mo}_{6} \mathrm{Cl}_{14}$, in $\mathrm{CH}_{3} \mathrm{CN}-\mathrm{CH}_{2} \mathrm{Cl}_{2} \quad(12 / 2 \mathrm{~mL})$ for [1a $]_{4} \mathrm{Mo}_{6} \mathrm{Cl}_{14}$, or in $\mathrm{CH}_{3} \mathrm{CN}(14 \mathrm{~mL})$ for $[\mathbf{1 a}]_{6} \mathrm{Mo}_{6} \mathrm{Cl}_{14}$ was used as electrolyte, with the donor 1a $(5 \mathrm{mg})$ dissolved in the anodic compartment. Electrolysis was performed during 7 days, after which air stable black-brown plate-shaped crystals were harvested on the anode. 
Table 5 Crystallographic data, details of data collection and structure refinement parameters

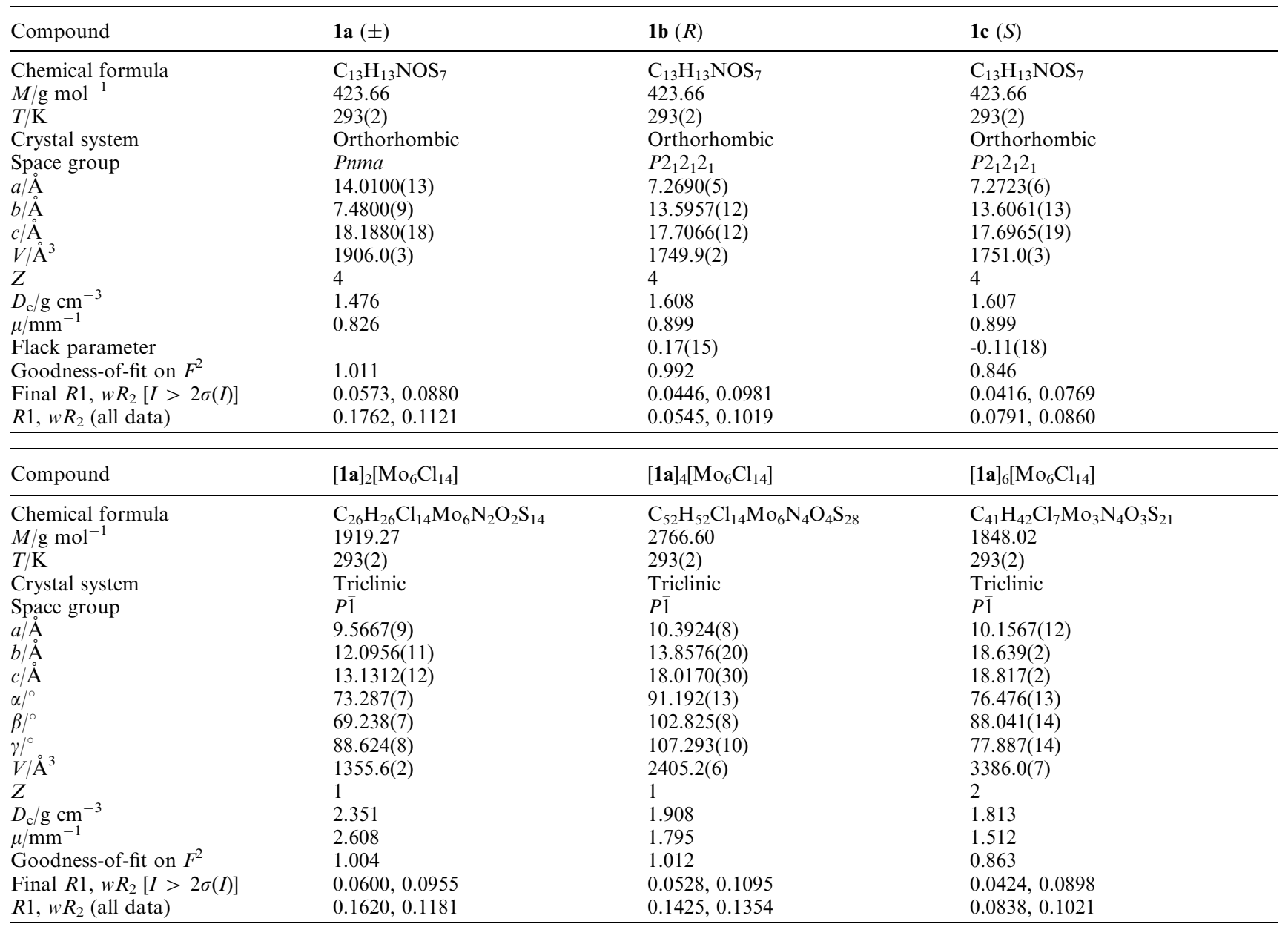

Theoretical calculations. The optimized geometries have been obtained with the Gaussian $03^{30}$ package at the DFT level of theory. The B3LYP functional ${ }^{31}$ with the $6-31+\mathrm{G}^{*}$ basis set has been used. Vibration frequency calculations performed on the optimized structures at the same level of theory yielded only positive values. AIM analyses were performed on B3LYP $/ 6-31+\mathrm{G}^{*}$ electron densities.

The tight-binding band structure calculations were of the extended Hückel type ${ }^{32 a}$ with a modified Wolfsberg-Helmholtz formula to calculate the non-diagonal $\mathrm{H}_{\mu \nu}$ values. ${ }^{32 b}$ The basis set consisted of double- $\zeta$ Slater-type orbitals for $\mathrm{C}, \mathrm{N}, \mathrm{O}$ and $\mathrm{S}$ and single- $\zeta$ Slater-type orbitals for $\mathrm{H}$. The exponents, contraction coefficients and ionization potentials were taken from previous work. ${ }^{33}$

Magnetic measurements. The magnetic susceptibility measurements were obtained with the use of a Quantum Design SQUID magnetometer MPMS-XL. Measurements were performed on a polycrystalline sample of $[\mathbf{1 a}]_{6} \mathrm{Mo}_{6} \mathrm{Cl}_{14}(9.81 \mathrm{mg})$. The magnetic data were corrected for the diamagnetic contribution of the sample and the sample holder, estimated from the Pascal's constants. ${ }^{34}$

Conductivity and thermoelectric power measurements. Electrical conductivity and thermoelectric power measurements were performed in the range $170-300 \mathrm{~K}$ on the same single crystal of $[\mathbf{1 a}]_{6} \mathrm{Mo}_{6} \mathrm{Cl}_{14}$, whereas in the case of $[\mathbf{1 a}]_{4} \mathrm{Mo}_{6} \mathrm{Cl}_{14}$ the conductivity could not be accurately measured because of large unnested voltages, therefore only the thermoelectric power was determined in the range $160-300 \mathrm{~K}$. In a first step thermopower was measured using a slow $\mathrm{AC}\left(\sim 10^{-2} \mathrm{~Hz}\right)$ technique by attaching to the extremities of the needle shaped crystals with platinum paint (Demetron $308 \mathrm{~A}$ ), two $\Phi=$

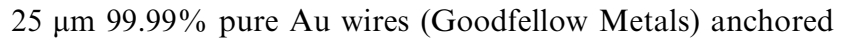
to two quartz thermal reservoirs. The oscillating thermal gradient was kept below $1 \mathrm{~K}$, and it was measured with a differential $\mathrm{Au}-0.05$ at. \% Fe vs. chromel thermocouple. The sample temperature was measured by a previously calibrated thermocouple of the same type. Both the differential thermocouple and the sample voltage were measured with Keithley 181 nanovoltmeters. The absolute thermopower of the sample was obtained after correction for the absolute thermopower of the Au leads, using the data of Huebner. ${ }^{35}$ In a second step, electrical resistivity measurements were performed on the same sample using a four-probe technique. Without removing the crystal from the sample holder, two extra Au wires were placed on the sample in order to achieve a four-in-line contact configuration. Prior to the measurements the sample was checked for unnested to nested voltage ratio, ${ }^{36}$ that was below $5 \%$ in the case of $[\mathbf{1 a}]_{6} \mathrm{Mo}_{6} \mathrm{Cl}_{14}$. Measurements were done 
imposing through the sample a current of $1 \mu \mathrm{A}$ at low frequency $(77 \mathrm{~Hz})$ and measuring the voltage drop with a lock-in amplifier.

Electrochemical studies. Cyclic voltammetry measurements were performed using a three-electrode cell equipped with a platinum millielectrode of $0.126 \mathrm{~cm}^{2}$ area, an $\mathrm{Ag} / \mathrm{Ag}^{+}$pseudoreference and a platinum wire counter-electrode. The potential values were then re-adjusted with respect to the saturated calomel electrode (SCE). The electrolytic media involved a $0.1 \mathrm{~mol} \mathrm{~L}^{-1}$ solution of $\left(n-\mathrm{Bu}_{4} \mathrm{~N}\right) \mathrm{PF}_{6}$ in $\mathrm{CH}_{2} \mathrm{Cl}_{2}$. All experiments have been performed at room temperature at $0.1 \mathrm{~V} \mathrm{~s}^{-1}$. Experiments have been carried out with an EGG PAR 273A potentiostat with positive feedback compensation.

\section{Acknowledgements}

Financial support from French Ministry of Education and Research to C. R., from Région Pays de la Loire to A. M. and from French Ministry of Foreign Affairs through a PICASSO (PAI 07125VE) and a PESSOA (PAI 10729NB) is gratefully acknowledged. R. C. thanks the CNRS, the University of Bordeaux 1, the French Ministries of Foreign Affairs and of Education and Research, and the Conseil Régional d'Aquitaine for financial supports. This work was also supported by CNRS (France) and by MEC-Spain (Project FIS2006-12117C04-01) and Generalitat de Catalunya (Project 2005 SGR 683).

\section{References}

1 (a) R. E. Rosenfield, Jr. and R. Parthasarathy, J. Am. Chem. Soc., 1977, 99, 4860-4862; (b) A. Kucsman and I. Kapovits, in Organic Sulfur Chemistry: Theoretical and Experimental Advances, eds. F. Bernardi, I. G. Csizmadia and A. Mangini, Elsevier Scientific Publishing Co., Amsterdam, 1985, pp. 191-245.

2 (a) J. Ángyán, R. A. Poirier, Á. Kucsman and I. G. Csizmadia, J. Am. Chem. Soc., 1987, 109, 2237-2245; (b) M. Iwaoka, S. Takemoto and S. Tomoda, J. Am. Chem. Soc., 2002, 124, 10613-10620.

3 (a) F. T. Burling and B. M. Goldstein, J. Am. Chem. Soc., 1992, 114, 2313-2320; (b) Y. Nagao, T. Hirata, S. Goto, S. Sano, A. Kakehi, K. Iizuka and M. Shiro, J. Am. Chem. Soc., 1998, 120, 3104-3110; (c) S. Wu and A. Greer, J. Org. Chem., 2000, 65, 4883-4887; (d) Y. Nagao, H. Iimori, S. Goto, T. Hirata, S. Sano, H. Chuman and M. Shiro, Tetrahedron Lett., 2002, 43, 1709-1712; (e) E. Meyer, A. C. Joussef, H. Gallardo, A. J. Bortoluzzi and R. L. Longo, Tetrahedron, 2003, 59, 10187-10193; (f) Y. Nagao, T. Honjo, H. Iimori, S. Goto, S. Sano, M. Shiro, K. Yamaguchi and Y. Sei, Tetrahedron Lett., 2004, 45, 8757-8761.

4 (a) J. C. Taylor and G. D. Markham, J. Biol. Chem., 1999, 274, 32909-32914; (b) W. Brandt, A. Golbraikh, M. Täger and U. Lendeckel, Eur. J. Biochem., 1999, 261, 89-97.

5 (a) M. Iwaoka, S. Takemoto, M. Okada and S. Tomoda, Chem. Lett., 2001, 132-133; (b) M. Iwaoka, S. Takemoto, M. Okada and S. Tomoda, Bull. Chem. Soc. Jpn., 2002, 73, 1611-1625.

6 (a) T. Suzuki, H. Fujii, Y. Yamashita, C. Kabuto, S. Tanaka, M. Harasawa, T. Mukai and T. Miyashi, J. Am. Chem. Soc., 1992, 114, 3034-3043; (b) M. Turbiez, P. Frère, M. Allain, C. Videlot, J. Ackermann and J. Roncali, Chem.-Eur. J., 2005, 11, 3742-3752; (c) A. F. Cozzolino, I. Vargas-Baca, S. Mansour and A. H. Mahmoudkhani, J. Am. Chem. Soc., 2005, 127, 3184-3190.

7 (a) W. Nakanishi, S. Hayashi and N. Itoh, Chem. Commun., 2003, 124-125; (b) W. Nakanishi, S. Hayashi and N. Itoh, J. Org. Chem., 2004, 69, 1676-1684.

8 (a) W. Nakanishi, S. Hayashi and S. Toyota, Chem. Commun., 1996, 371-372; (b) W. Nakanishi, S. Hayashi and T. J. Uehara, Phys. Chem. A, 1999, 103, 9906-9912; (c) W. Nakanishi and S.
Hayashi, J. Org. Chem., 2002, 67, 38-48; (d) W. Nakanishi, S. Hayashi and T. Arai, Chem. Commun., 2002, 2416-2417; (e) W. Nakanishi, T. Nakamoto, S. Hayashi, T. Sasamori and N. Tokitoh, Chem.-Eur. J., 2007, 13, 255-268.

9 C. Bleiholder, D. B. Werz, H. Köppel and R. Gleiter, J. Am. Chem. Soc., 2006, 128, 2666-2674.

10 G. Raos, A. Famulari, S. V. Meille, M. C. Gallazzi and G. Allegra, J. Phys. Chem. A, 2004, 108, 691-698.

11 (a) R. F. W. Bader, Atoms in Molecules-A Quantum Theory, Oxford University Press, Oxford, 1990; (b) R. F. W. Bader, Chem. Rev., 1991, 91, 893-928.

12 (a) J. L. Segura and N. Martin, Angew. Chem., Int. Ed., 2001, 40, 1372-1409; (b) J.-L. Yamada, TTF Chemistry: Fundamentals and Applications of Tetrathiafulvalene, Springer-Verlag, Berlin and Heidelberg, 2004

13 (a) J. M. Williams, J. R. Ferraro, R. J. Thorn, K. D. Carlson, U. Geiser, H. H. Wang, A. M. Kini and M.-H. Whangbo, in Organic Superconductors (Including Fullerenes), Synthesis, Structure, Properties and Theory, ed. R. N. Grimes, Prentice-Hall, Englewoods Cliffs, NJ, 1992; (b) T. Ishiguro, K. Yamaji and G. Saito, Organic Superconductors, Springer-Verlag, Heidelberg, 1998.

14 (a) C. Réthoré, M. Fourmigué and N. Avarvari, Chem. Commun., 2004, 1384-1385; (b) C. Réthoré, M. Fourmigué and N. Avarvari, Tetrahedron, 2005, 61, 10935-10942.

15 C. Réthoré, N. Avarvari, E. Canadell, P. Auban-Senzier and M. Fourmigué, J. Am. Chem. Soc., 2005, 127, 5748-5749.

16 (a) G. Mugesh, H. B. Singh and R. J. Butcher, Eur. J. Inorg. Chem., 1999, 1229-1236; (b) G. Mugesh, A. Panda, H. B. Singh and R. J. Butcher, Chem.-Eur. J., 1999, 5, 1411-1421; (c) K. Kandasamy, S. Kumar, H. B. Singh, R. J. Butcher and K. Travis Holman, Eur. J. Inorg. Chem., 2004, 1014-1023.

17 (a) W. Dölling, K. Friedemann, F. Heinemann and H. Hartung, Z. Naturforsch., B: Chem. Sci., 1991, 46, 1251-1257; (b) F. W. Heinemann, W. Dölling and H. Hartung, J. Chem. Crystallogr., 1995, 25, 463-467.

18 P. Blanchard, M. Sallé, G. Duguay, M. Jubault and A. Gorgues, Tetrahedron Lett., 1992, 33, 2685-2688.

19 I. V. Sudmale, G. V. Tormos, V. Y. Khodorkovsky, A. S. Edzina, O. J. Neilands and M. P. Cava, J. Org. Chem., 1993, 58, 1355-1358.

20 A. Bondi, J. Phys. Chem., 1964, 68, 441.

21 (a) J. Poater, M. Solà and F. M. Bickelhaupt, Chem.-Eur. J., 2006, 12, 2889-2895; (b) R. F. W. Bader, Chem.-Eur. J., 2006, 12, 2896-2901; (c) J. Poater, M. Solà and F. M. Bickelhaupt, Chem.-Eur. J., 2006, 12, 2902-2905.

22 (a) U. Koch and P. L. A. Popelier, J. Phys. Chem., 1995, 99, 9747-9754; (b) P. L. A. Popelier, J. Phys. Chem. A, 1998, 102, 1873-1878; (c) A. Hocquet, Phys. Chem. Chem. Phys., 2001, 3, 3192-3199.

23 R. G. A. Bone and R. F. W. Bader, J. Phys. Chem., 1996, 100, 10892-10911.

24 P. Sanz, O. Mó and M. Yánez, Phys. Chem. Chem. Phys., 2003, 5, 2942-2947.

25 K. B. Wiberg, R. F. W. Bader and C. D. H. Lau, J. Am. Chem. Soc., 1987, 109, 1001-1012.

26 T. Chivers, I. Krouse, M. Parvez, I. Vargas-Baca, T. Ziegler and P. Zoricak, Inorg. Chem., 1996, 35, 5836-5842.

27 M.-H. Whangbo, J. M. Williams, P. C. W. Leung, M. A. Beno, T. J. Emge and H. H. Wang, Inorg. Chem., 1985, 24, 35003502 .

28 (a) H. Fritzsche, Solid State Commun., 1971, 9, 1813-1815; (b) E. Coronado, J. R. Galán-Mascarós, C. Giménez-Saiz, C. J. GómezGarcia, E. Martinez-Ferrero, M. Almeida, E. B. Lopes, S. C. Capelli and R. M. Llusar, J. Mater. Chem., 2004, 14, 1867-1872; (c) E. Ribera, C. Rovira, J. Veciana, J. Tarrés, E. Canadell, R. Rousseau, E. Molins, M. Mas, J. P. Schoeffel, J.-P. Pouget, J. Morgado, V. Gama, R. T. Henriques and M. Almeida, Synth. Met., 1999, 102, 1743-1746.

29 G. M. Sheldrick, Programs for the Refinement of Crystal Structures, University of Göttingen, Göttingen, Germany, 1996.

30 M. J. Frisch, G. W. Trucks, H. B. Schlegel, G. E. Scuseria, M. A. Robb, J. R. Cheeseman, J. A. Montgomery, Jr., T. Vreven, K. N. Kudin, J. C. Burant, J. M. Millam, S. S. Iyengar, J. Tomasi, V. Barone, B. Mennucci, M. Cossi, G. Scalmani, N. Rega, G. A. Petersson, H. Nakatsuji, M. Hada, M. Ehara, K. Toyota, 
R. Fukuda, J. Hasegawa, M. Ishida, T. Nakajima, Y. Honda, O. Kitao, H. Nakai, M. Klene, X. Li, J. E. Knox, H. P. Hratchian, J. B. Cross, V. Bakken, C. Adamo, J. Jaramillo, R. Gomperts, R. E. Stratmann, O. Yazyev, A. J. Austin, R. Cammi, C. Pomelli, J. Ochterski, P. Y. Ayala, K. Morokuma, G. A. Voth, P. Salvador, J. J. Dannenberg, V. G. Zakrzewski, S. Dapprich, A. D. Daniels, M. C. Strain, O. Farkas, D. K. Malick, A. D. Rabuck, K. Raghavachari, J. B. Foresman, J. V. Ortiz, Q. Cui, A. G. Baboul, S. Clifford, J. Cioslowski, B. B. Stefanov, G. Liu, A. Liashenko, P. Piskorz, I. Komaromi, R. L. Martin, D. J. Fox, T. Keith, M. A. Al-Laham, C. Y. Peng, A. Nanayakkara, M. Challacombe, P. M. W. Gill, B. G. Johnson, W. Chen, M. W. Wong, C. Gonzalez and J. A. Pople, GAUSSIAN 03 (Revision B.03), Gaussian, Inc., Wallingford, CT, 2004.
31 (a) C. Lee, W. Yang and R. G. Parr, Phys. Rev. B, 1988, 37, 785-789; (b) A. D. Becke, J. Chem. Phys., 1993, 98, 5648-5652.

32 (a) M.-H. Whangbo and R. Hoffmann, J. Am. Chem. Soc., 1978, 100, 6093-6098; (b) J. H. Ammeter, H.-B. Bürgi, J. Thibeault and R. Hoffmann, J. Am. Chem. Soc., 1978, 100, 3686-3692.

33 (a) A. Pénicaud, K. Boubekeur, P. Batail, E. Canadell, P. AubanSenzier and D. Jérome, J. Am. Chem. Soc., 1993, 115, 4101-4112; (b) S. A. Baudron, N. Avarvari, E. Canadell, P. Auban-Senzier and P. Batail, Chem.-Eur. J., 2004, 10, 4498-4511.

34 E. A. Boudreaux and L. N. Mulay, Theory and Applications of Molecular Magnetism, John Wiley \& Sons, New York, 1976.

35 R. P. Huebner, Phys. Rev. A, 1964, 135, 1281.

36 P. E. Schaffer, F. Wudl, G. A. Thomas, J. P. Ferraris and D. O. Cowan, Solid State Commun., 1974, 14, 347-351. 